\title{
Effect of aluminum and sodium on the sorption of water and methanol in microporous MFI-type zeolites and mesoporous SBA-15 materials
}

\author{
Zheng $\mathrm{Li}^{1} \cdot$ Carolin Rieg $^{1} \cdot$ Ann-Katrin Beurer ${ }^{1} \cdot$ Michael Benz ${ }^{1} \cdot$ Johannes Bender $^{2} \cdot$ Christof Schneck $^{3} \cdot$ Yvonne Traa $^{1}$. \\ Michael Dyballa ${ }^{1}$ (D) Michael Hunger ${ }^{1}$
}

Received: 6 May 2020 / Revised: 27 July 2020 / Accepted: 26 September 2020 / Published online: 6 October 2020

(c) The Author(s) 2020

\begin{abstract}
The interaction and nature of surface sites for water and methanol sorption on MFI-type zeolites and mesoporous SBA-15 were investigated by solid-state NMR spectroscopy and correlated with the desorption enthalpies determined via TGA/DSC. For siliceous Silicalite-1, ${ }^{29} \mathrm{Si}$ CPMAS NMR studies support stronger methanol than water interactions with SiOH groups of $\mathrm{Q}^{3}$-type. On siliceous SBA-15, $\mathrm{SiOH}$ groups of $\mathrm{Q}^{2}$-type are accompanied by an enhanced hydrophilicity. In aluminumcontaining Na-ZSM-5, $\mathrm{Na}^{+}$cations are strong adsorption sites for water and methanol as evidenced by ${ }^{23} \mathrm{Na}$ MAS NMR in agreement with high desorption enthalpies of $\Delta H=66-74 \mathrm{~kJ} / \mathrm{mol}$. Solid-state NMR of aluminum-containing Na-[Al]SBA15 , in contrast, has shown negligible water and methanol interactions with sodium and aluminum. Desorption enthalpies of $\Delta H=44-60 \mathrm{~kJ} / \mathrm{mol}$ hint at adsorption sites consisting of SiOH groups influenced by distant framework aluminum. On H-ZSM-5, Brønsted acidic OH groups are strong adsorption sites as indicated by partial protonation of water and methanol causing low-field shifts of their ${ }^{1} \mathrm{H}$ MAS NMR signals and enhanced desorption enthalpies. Due to the small number of Brønsted acid sites in aluminum-containing $\mathrm{H}$-[Al]SBA-15, water and methanol adsorption on this material is suggested to mainly occur at $\mathrm{SiOH}$ groups with distant framework aluminum species, as in the case of Na-[Al]SBA-15.
\end{abstract}

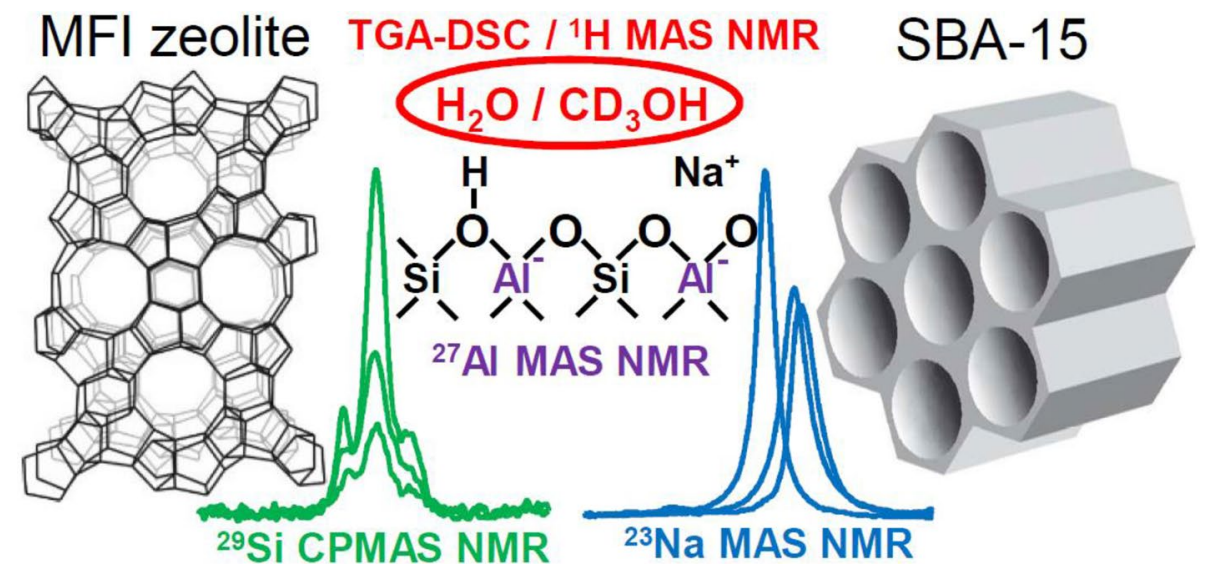

Keywords Water adsorption $\cdot$ Methanol adsorption $\cdot$ MFI-type zeolites $\cdot$ Mesoporous SBA-15 $\cdot$ Solid-state NMR spectroscopy $\cdot$ Desorption enthalpies

Electronic supplementary material The online version of this article (https://doi.org/10.1007/s10450-020-00275-8) contains supplementary material, which is available to authorized users.

Michael Dyballa

michael.dyballa@itc.uni-stuttgart.de

Extended author information available on the last page of the article

\section{Introduction}

In the past decades, numerous studies were dealing with the adsorption properties of water and alcohols on porous solids. Often, these investigations focused on water and ethanol due to the application of porous solids with hydrophobic and 
organophilic properties in separation processes (Caro and Noack 2008). Because of the raising industrial application of the methanol to hydrocarbon conversion on acidic zeolite catalysts (Olsbye et al. 2012; Tian et al. 2015), which is accompanied by the formation of water, it is also interesting to clarify the adsorption properties of methanol and to compare them with those of water. Another application is the desorption of surface-bound methanol from zeolites in the presence of water, for example after methane oxidation to methanol (Dyballa et al. 2019a, b; Pappas et al. 2017; Ravi et al. 2017). The presence of bulk species and the interaction sites of water and methanol are also of interest for improving the stability of zeolites and related materials of different pore size, as the interaction sites like silanols can react with water at higher temperatures and damage the framework (Kalantzopoulos et al. 2018, 2020; Prodinger et al. 2016).

An often utilized experimental approach for the investigation of the adsorption properties of potential reactants on solid supports is the determination of adsorption heats and desorption enthalpies, e.g. via calorimetric or temperatureprogrammed desorption techniques. For water and methanol adsorption on MFI-type materials, such as Silicalite-1, Na-ZSM-5, and H-ZSM-5, adsorption heats covering the range of $20-80 \mathrm{~kJ} / \mathrm{mol}$ have been determined (Hunger et al. 1995a, 1997a; Lee et al. 1997; Pope 1993). The evaporation heat of $41 \mathrm{~kJ} / \mathrm{mol}$ for liquid water (Flanigen et al. 1978) and $37 \mathrm{~kJ} / \mathrm{mol}$ for liquid methanol (Schmeling and Strey 1983) are within this range. General tendencies are weaker adsorption heats, respectively, desorption enthalpies for water and methanol molecules, e.g., adsorbed by $\mathrm{H}$-bondings at $\mathrm{SiOH}$ groups [ $\mathrm{H}_{2} \mathrm{O}: 20 \mathrm{~kJ} / \mathrm{mol}$ (Lee et al. 1997), $\mathrm{CH}_{3} \mathrm{OH}: 38-48 \mathrm{~kJ} /$ mol (Pope 1993)] and higher values for water and methanol molecules adsorbed at $\mathrm{Na}^{+}$cations $\left[\mathrm{H}_{2} \mathrm{O}: 60-80 \mathrm{~kJ} /\right.$ mol (Hunger et al. 1995a), $\mathrm{CH}_{3} \mathrm{OH}: 65-80 \mathrm{~kJ} / \mathrm{mol}$ (Hunger et al. 1997a)] or Brønsted acidic bridging $\mathrm{OH}$ groups $\left[\mathrm{H}_{2} \mathrm{O}: 50-60 \mathrm{~kJ} / \mathrm{mol}\right.$ (Hunger et al. 1995a), $\mathrm{CH}_{3} \mathrm{OH}: 50-65 \mathrm{~kJ} /$ mol (Hunger et al. 1997a), etc.] in ZSM-5 zeolites loaded with low amounts of adsorbate. However, higher adsorbate loadings are often accompanied by strong variations of the adsorption heats and desorption enthalpies, respectively. Therefore, they do not allow a detailed insight into the properties of the adsorption sites and the nature of the adsorbate complexes.

The aim of the present work is to combine the study of water and methanol sorption on Silicalite-1, Na-ZSM-5, and H-ZSM-5. Therefore, we determine the desorption enthalpies via TGA/DSC and investigate the nature and properties of adsorption sites and adsorbate complexes via solid-state NMR spectroscopy under similar conditions. By this combined approach, new insights into the state and nature of water and methanol for different loadings and their specific desorption enthalpies could be obtained. Subsequently, the demonstrated methods have been utilized for investigating the influence of the introduction of aluminum into mesoporous SBA-15 materials on their water and methanol adsorption properties. These studies were combined with a detailed solid-state NMR investigation of potential adsorption sites of the above-mentioned MFI-type zeolites and mesoporous SBA-15 materials. By the study of these samples saturated at room temperature with water or methanol, the properties of these adsorbate molecules existing as bulk clusters inside the pores have been clarified, while upon desorption at $373 \mathrm{~K}$, the adsorbate molecules remaining directly at the sorption sites and at the inner pore surface were available for investigations. Finally, samples evacuated at $723 \mathrm{~K}$ allowed an insight into the hydroxyl coverage without any adsorbate molecules.

Despite numerous solid-state NMR studies of water and methanol on various zeolites and other solid support materials, to the best of our knowledge, no direct spectroscopic comparison of these two adsorbate molecules on identical samples or on comparable samples with different pore sizes was performed until now. On the other hand, previous solidstate NMR studies of water or methanol adsorption on solid catalysts gave useful insights into the possible states and natures of the above-mentioned adsorbate complexes and delivered valuable spectroscopic parameters, which are helpful for the assignment and discussion of the solid-state NMR signals observed in the present work.

According to previous studies, water vapour gives a ${ }^{1} \mathrm{H}$ NMR signal at the chemical shift of $0.31 \mathrm{ppm}$ (Harris and Mann 1978), while the signal of bulk water occurs at $4.78 \mathrm{ppm}$ (Emsley et al. 1965). The difference in the resonance position is due to the H-bondings between the molecules in water clusters. Water adsorbed at $\mathrm{Na}^{+}$cations, such as existing in aluminosilicates for the compensation of negative framework charges, is observed at $3.5 \mathrm{ppm}$ (Kasai and Jones 1984). In zeolites containing Brønsted acid sites [Si-(OH)-Al], adsorbed water can be protonated and forms hydroxonium ions, which leads to ${ }^{1} \mathrm{H}$ MAS NMR signals at $9 \mathrm{ppm}$ in a hydrated state (Wang et al. 2019). For comparison, the signal of hydroxonium protons in $\mathrm{H}_{3} \mathrm{OClO}_{4}$ was observed at $10.7 \mathrm{ppm}$, while the signal of hydroxonium protons at the $\mathrm{K}^{+}$position in alunite mineral occurs at $11.4 \mathrm{ppm}$ (Ratcliffe et al. 1985). By quantum-chemical methods, a resonance position of $12.7 \mathrm{ppm}$ was calculated for single water ion pairs $\left(\mathrm{H}_{3} \mathrm{O}^{+} / \mathrm{Si}-\mathrm{O}-\mathrm{Al}^{-}\right)$(Haase and Sauer 1994).

The chemical shift of the ${ }^{1} \mathrm{H}$ NMR signal of the hydroxyl proton of methanol in $\mathrm{CDCl}_{3}$ was determined to $1.6 \mathrm{ppm}$ and due to H-bondings in liquid $\mathrm{CD}_{3} \mathrm{OH}$ to $4.73 \mathrm{ppm}$, whereas in the case of methanol adsorption at $\mathrm{Na}^{+}$cations in zeolites, a signal at $3.6 \mathrm{ppm}$ occurs (Anderson et al. 1991). These chemical shift values are very similar to the values determined for water adsorption under similar conditions. However, quantum-chemical calculation of hydrogen bonded methanol and methanol in ion pairs $\left(\mathrm{CH}_{3} \mathrm{OH}_{2}{ }^{+} / \mathrm{Si}-\mathrm{O}-\mathrm{Al}^{-}\right)$ 
gave resonance positions of $10.8 \mathrm{ppm}$ and $17.4 \mathrm{ppm}$, respectively (Haase and Sauer 1995).

According to the above-mentioned chemical shift values, the ${ }^{1} \mathrm{H}$ NMR signals of water in different adsorption states on solid catalysts cover a range from $0 \mathrm{ppm}$ (highly diluted/ vapour) to maximum $13 \mathrm{ppm}$ (hydroxonium ions), while for methanol in similar adsorption states, a range from $1 \mathrm{ppm}$ (highly diluted) to maximum $17 \mathrm{ppm}$ (methoxonium ions) has to be expected. At room temperature, rapid exchange occurs between the different adsorption states of water and methanol on solid catalysts. Therefore, the resonance positions of the maxima of the experimentally observed ${ }^{1} \mathrm{H}$ MAS NMR signals depend on the relative contents of all contributing adsorbate complexes and their characteristic chemical shifts. Due to this effect, e.g. the experimentally observed ${ }^{1} \mathrm{H}$ MAS NMR signals of methanol (methoxonium ions:17.4 ppm) (Haase and Sauer 1995) in rapid exchange with these molecules adsorbed at strong Brønsted acid sites in zeolites can reach higher chemical shift values compared with water (hydroxonium ions:12.7 ppm) (Haase and Sauer 1994) under similar conditions. Furthermore, the mobility of the adsorbate molecules limits the effect of the line narrowing by rapid sample spinning around an axis in the magic angle (MAS). Therefore, the line widths of ${ }^{1} \mathrm{H}$ MAS NMR signals of adsorbed water and methanol molecules strongly depend on the dynamic of exchange processes and the molecule mobility.

\section{Experimental methods}

\subsection{Preparation of materials}

Zeolite H-ZSM-5 was purchased from Tricat Inc., Hunt Valley, USA. Na-ZSM-5 was obtained by triple ion exchange of H-ZSM-5. Briefly, $30 \mathrm{~g} \mathrm{H}-Z \mathrm{SM}-5$ was mixed with $600 \mathrm{~mL}$ $1 \mathrm{M} \mathrm{NaNO}_{3}$ solution, stirred at $323 \mathrm{~K}$ for $4 \mathrm{~h}$, filtered and washed with deionized water. Silicalite-1 was synthesized as reported by Ghamami and Sand (1983) in a rotating autoclave using a Levasil $200 \mathrm{~N}$ sol as silica source. Further informations on shape and properties of these materials can be found elsewhere (Dyballa et al. 2016).

The siliceous SBA-15 was synthesized according to literature (Meynen et al. 2009). Briefly, $4 \mathrm{~g} \mathrm{P} 123$ were dissolved in $130 \mathrm{~mL} \mathrm{H}_{2} \mathrm{O}$ and $20 \mathrm{~mL} 37 \% \mathrm{HCl}$ solution. $9.14 \mathrm{~mL}$ tetraethyl orthosilicate (TEOS) were added into the solution, stirred at $318 \mathrm{~K}$ for $7.5 \mathrm{~h}$ and aged at $353 \mathrm{~K}$ for $15.5 \mathrm{~h}$. The as-synthesized material was washed with demineralized water and calcined at $823 \mathrm{~K}$ for $6 \mathrm{~h}$. The modification of SBA-15 with aluminum has been reported elsewhere (Luan et al. 1999). Briefly, $0.24 \mathrm{~g}$ sodium aluminate was mixed with $2 \mathrm{~g}$ SBA-15, added to $200 \mathrm{~mL}$ water and stirred at $295 \mathrm{~K}$ for $16 \mathrm{~h}$. Na-[Al]SBA- 15 was obtained after washing with demineralized water and subsequent calcination at $823 \mathrm{~K}$ for $5 \mathrm{~h}$. H-[Al]SBA- 15 was obtained after two-fold ion exchange of $0.7 \mathrm{~g} \mathrm{Na}$-[Al]SBA- 15 in $50 \mathrm{~mL}$ $1 \mathrm{M} \mathrm{NH}_{4} \mathrm{NO}_{3}$ solution at $353 \mathrm{~K}$ for $4 \mathrm{~h}$ and subsequent calcination at $673 \mathrm{~K}$ for $6 \mathrm{~h}$.

\subsection{Analytical and spectroscopic methods}

The chemical composition of the samples under study was determined by inductively coupled plasma emission spectrometry (ICP-OES) on an IRIS Advantage instrument. X-ray diffraction (XRD) patterns were recorded by using a Bruker $\mathrm{D} 8$ diffractometer with $\mathrm{CuK} \alpha$ radiation $\left(\lambda=1.5418 \AA\right.$ ) in the $2 \Theta$ range of $4^{\circ}-50^{\circ}$ for MFI zeolites and $0.7^{\circ}-5^{\circ}$ for SBA- 15 . The surface areas of different porous materials were measured by nitrogen physisorption at $77 \mathrm{~K}$ on a Quantachrome Autosorb 3B device and calculated according to the Brunauer-Emmett-Teller (BET) equation. Mesopore volumes were calculated from the total pore volume at $p / p_{0}=0.99$ and the micropore volume according to the V-t method (deBoer). Mesopore diameters were obtained via the Barrett-Joyner-Halenda (BJH) method from the adsorption branch. Before nitrogen adsorption, the samples were activated in vacuum at $623 \mathrm{~K}$ for $16 \mathrm{~h}$. Thermogravimetric analysis (TGA) and differential scanning calorimetry (DSC) curves were simultaneously measured on a Netzsch STA 449 F5 instrument. Before the experiments, the differential scanning calorimeter was calibrated by a standard calibration kit. For these measurements, 5 to $11 \mathrm{mg}$ of samples, saturated with water or methanol at $295 \mathrm{~K}$ for $48 \mathrm{~h}$, were filled into aluminum crucibles and sealed with a lid with pinned hole. The temperature program of TGA-DSC measurement contained two heating steps, $298-373 \mathrm{~K}(1 \mathrm{~K} / \mathrm{min})$ and $373-723 \mathrm{~K}(5 \mathrm{~K} / \mathrm{min})$ for determining the weakly and strongly adsorbed molecules, respectively. An isothermal step at $373 \mathrm{~K}$ ( $60 \mathrm{~min})$ and cooling step from 373 to $348 \mathrm{~K}$ ( $5 \mathrm{~min}$ ) was conducted in between these two heating ramps. A repetition of the heating steps was performed to create a baseline for the DSC curve and the desorption enthalpies determined as described elsewhere (Kim et al. 2016).

The ${ }^{1} \mathrm{H},{ }^{23} \mathrm{Na}$, and ${ }^{27} \mathrm{Al}$ MAS NMR measurements were carried out on a Bruker Avance III 400WB spectrometer using a $4.0 \mathrm{~mm}$ MAS NMR probe with a spinning rate of $8 \mathrm{kHz} .{ }^{1} \mathrm{H},{ }^{23} \mathrm{Na}$, and ${ }^{27} \mathrm{Al}$ MAS NMR spectra were recorded at the resonance frequencies of $400.1 \mathrm{MHz}, 105.8 \mathrm{MHz}$, and 104.2 MHz, respectively, with single-pulse $\pi / 2\left({ }^{1} \mathrm{H}\right)$, $\pi / 4\left({ }^{23} \mathrm{Na}\right)$, and $\pi / 6\left({ }^{27} \mathrm{Al}\right)$ excitation, and repetition times of $20 \mathrm{~s}$ for ${ }^{1} \mathrm{H}$ and $0.5 \mathrm{~s}$ for ${ }^{23} \mathrm{Na}$ and ${ }^{27} \mathrm{Al}$ nuclei. The ${ }^{29} \mathrm{Si}$ crosspolarization MAS NMR measurements (CPMAS NMR) were carried out using a $7.0 \mathrm{~mm}$ MAS NMR probe with a spinning rate of $3.5 \mathrm{kHz}$. These spectra were recorded at the resonance frequency of $79.5 \mathrm{MHz}$ (same spectrometer) at an optimized RF-field of $41.67 \mathrm{kHz}$ with a ${ }^{1} \mathrm{H}-{ }^{29} \mathrm{Si}$ contact 
time of $3 \mathrm{~ms}$ and a repetition time of $4 \mathrm{~s}$ applying a ramp of $70-100 \%$ and tppm 15 decoupling. TopSpin software was used to determine the quadrupole parameters.

Before adsorption of water or methanol, the samples were calcined at $723 \mathrm{~K}$ for $12 \mathrm{~h}$ and at $p<10^{-2}$ mbar using a vacuum line. The adsorption of $\mathrm{H}_{2} \mathrm{O}$ was performed at $295 \mathrm{~K}$ for $48 \mathrm{~h}$ by equilibrating calcined samples in a desiccator over saturated $\mathrm{Ca}\left(\mathrm{NO}_{3}\right)_{2}$ solution. The adsorption of methanol was performed at $295 \mathrm{~K}$ for $48 \mathrm{~h}$ by equilibrating calcined samples in a Schlenk line containing $\mathrm{CD}_{3} \mathrm{OH}$. For some of the MAS NMR studies, water- and methanol-loaded samples were evacuated at $373 \mathrm{~K}$ for $30 \mathrm{~min}$. This final temperature was reached by increasing the temperature from $298 \mathrm{~K}$ in steps of $25 \mathrm{~K}$ up to $373 \mathrm{~K}$ with an equilibration for $30 \mathrm{~min}$ at each step. The samples were transferred into the $4 \mathrm{~mm}$ or $7 \mathrm{~mm}$ MAS NMR rotors inside a glove box purged with dry nitrogen gas. For ammonia loading, calcined samples were packed in $\mathrm{ZrO}_{2}$ rotors and via a glass tube connected to a vacuum line. After evacuation, $\mathrm{NH}_{3}$ was loaded with a pressure of $100 \mathrm{mbar}$ for $10 \mathrm{~min}$. Subsequently, desorption of physisorbed $\mathrm{NH}_{3}$ was performed in vacuum at $453 \mathrm{~K}$ for $2 \mathrm{~h}$.

\section{Results and discussion}

\subsection{Physico-chemical characterization}

The chemical compositions of the samples under study, determined by ICP-OES, and the results of the $\mathrm{N}_{2}$ physisorption studies are summarized in Table 1. As can be seen, only negligible traces of aluminum were found in the siliceous materials Silicalite-1 and SBA-15. Furthermore, both the $\mathrm{H}$ - and Na-form of ZSM-5 and the aluminum-modified SBA-15 materials show equal aluminum contents. Thus, the ion exchange process did not lead to a significant removal of aluminum in either case. Only negligible amounts of sodium were found for $\mathrm{H}-\mathrm{ZSM}-5$ and $\mathrm{H}-[\mathrm{Al}] \mathrm{SBA}-15$, i.e. the $\mathrm{H}$-forms of these materials were completely ion exchanged.
The BET surface areas of MFI-type zeolites are between 345 and $372 \mathrm{~m}^{2} / \mathrm{g}$ and thus in the typical range for these materials, with negligible mesopore volumes (Dyballa et al. 2016, 2018a). Upon modification of the siliceous SBA-15 with sodium aluminate, the BET surface area decreased from 870 to $522 \mathrm{~m}^{2} / \mathrm{g}$ for Na-[Al]SBA-15 and of $442 \mathrm{~m}^{2} / \mathrm{g}$ for $\mathrm{H}-[\mathrm{Al}] \mathrm{SBA}-15$. Simultaneously, the micropore volume decreased from 0.14 to $0.05-0.03 \mathrm{~mL} / \mathrm{g}$ and mesopore volume decreased from 0.93 to $0.75-0.72 \mathrm{~mL} / \mathrm{g}$. This was accompanied by a change of the average mesopore diameter from 7.1 to $6.7-6.8 \mathrm{~nm}$ (accuracy \pm 0.1 ). This results from aluminum deposits in micropores and few aluminum deposits inside the mesopores and agrees with observations of other authors (Talha et al. 2017).

To verify the phase purity of the materials, X-ray diffraction on MFI zeolites and mesoporous SBA-15 materials was performed. The corresponding diffraction patterns are depicted in Figures S1 and S2, respectively, in the Supporting Information. Figure S1 shows typical diffraction patterns of MFI-type zeolites, without reflections due to competing phases. The small angle X-ray diffraction patterns of SBA-15 and aluminum modified SBA-15 show the typical reflections of the hexagonal symmetry known from literature (Talha et al. 2017). Thus, the phase purity of both micro- and mesoporous materials was confirmed.

The ${ }^{27}$ Al MAS NMR spectra of the siliceous materials in Figure S3 in the Supporting Information contain only traces of aluminum species, which is in accordance with the ICP-OES results in Table 1. The crystalline MFI zeolites show ${ }^{27} \mathrm{Al}$ MAS NMR signals at $55 \mathrm{ppm}$ due to tetrahedral aluminum $\left(\mathrm{Al}^{\mathrm{IV}}\right)$ incorporated in the framework and negligible signals at 0 ppm due to octahedrally coordinated extraframework aluminum (Al ${ }^{\mathrm{VI}}$ ). Mesoporous Na-[Al]SBA-15 has a peak of $\mathrm{Al}^{\mathrm{IV}}$ and no peak of $\mathrm{Al}^{\mathrm{VI}}$. The $\mathrm{Al}^{\mathrm{IV}}$ signal is strongly broadened as a result of the amorphous nature of the pore walls. Furthermore, the presence of small amounts of pentahedral aluminum $\left(\mathrm{Al}^{\mathrm{V}}\right)$ at a chemical shift of ca. $30 \mathrm{ppm}$ is verified. Mesoporous $\mathrm{H}-[\mathrm{Al}] \mathrm{SBA}-15$ shows in

Table 1 Physicochemical properties of the materials under study

\begin{tabular}{|c|c|c|c|c|c|c|c|}
\hline Material & $\mathrm{Si} / \mathrm{Al} \mathrm{ratio}^{\mathrm{a}}$ & $\begin{array}{l}\text { Al content in } \\
\mathrm{mmol} / \mathrm{g}^{\mathrm{a}}\end{array}$ & $\begin{array}{l}\text { Na content in } \\
\mathrm{mmol} / \mathrm{g}^{\mathrm{a}}\end{array}$ & $\begin{array}{l}\text { BET surface } \\
\text { in } \mathrm{m}^{2} / \mathrm{g}\end{array}$ & $\mathrm{V}_{\text {micro }}$ in $\mathrm{mL} / \mathrm{g}$ & $\mathrm{V}_{\text {meso }}$ in $\mathrm{mL} / \mathrm{g}$ & $\begin{array}{l}\text { Mesopore } \\
\text { diameter in } \\
\mathrm{nm}^{\mathrm{b}}\end{array}$ \\
\hline Silicalite-1 & $>800$ & $<0.01$ & $<0.01$ & 350 & 0.12 & 0.10 & - \\
\hline Na-ZSM-5 & 24 & 0.60 & 0.60 & 345 & 0.12 & 0.06 & - \\
\hline H-ZSM-5 & 24 & 0.60 & $<0.01$ & 372 & 0.13 & 0.07 & - \\
\hline SBA-15 & $>1600$ & $<0.01$ & $<0.01$ & 870 & 0.14 & 0.93 & 7.1 \\
\hline $\mathrm{Na}-[\mathrm{Al}] \mathrm{SBA}-15$ & 12 & 1.11 & 0.86 & 522 & 0.05 & 0.75 & 6.7 \\
\hline H-[Al]SBA-15 & 12 & 1.15 & $<0.01$ & 442 & 0.03 & 0.72 & 6.8 \\
\hline
\end{tabular}

${ }^{\text {a }}$ Determined by ICP-OES with experimental accuracy of $\pm 10 \%$

${ }^{\mathrm{b}}$ Adsorption branch 
addition to the signal observed for $\mathrm{Na}-[\mathrm{Al}] \mathrm{SBA}-15$, the formation of $\mathrm{Al}^{\mathrm{VI}}$ species in result of the $\mathrm{NH}_{4}{ }^{+}$exchange and the subsequent calcination. We found no evidence of dealumination caused by the loadings with water respectively methanol. Hence, the synthesis of pure and intact MFI- type zeolites and SBA-15 materials was verified.

\subsection{Spectroscopic investigation of the different adsorption sites in MFI-type zeolites and mesoporous SBA-15}

Potential adsorption sites for water and methanol, which can occur in MFI-type zeolites and SBA-15 materials with different aluminum contents are graphically summarized in Scheme 1.

For the siliceous materials Silicalite-1 and SBA-15, isolated $\left(\mathrm{Q}^{3}\right)$, vicinal $\left(\mathrm{Q}^{3}\right.$, not shown), and geminal $\left(\mathrm{Q}^{2}\right)$ $\mathrm{SiOH}$ groups (Scheme 1a and b, right-hand side) may act
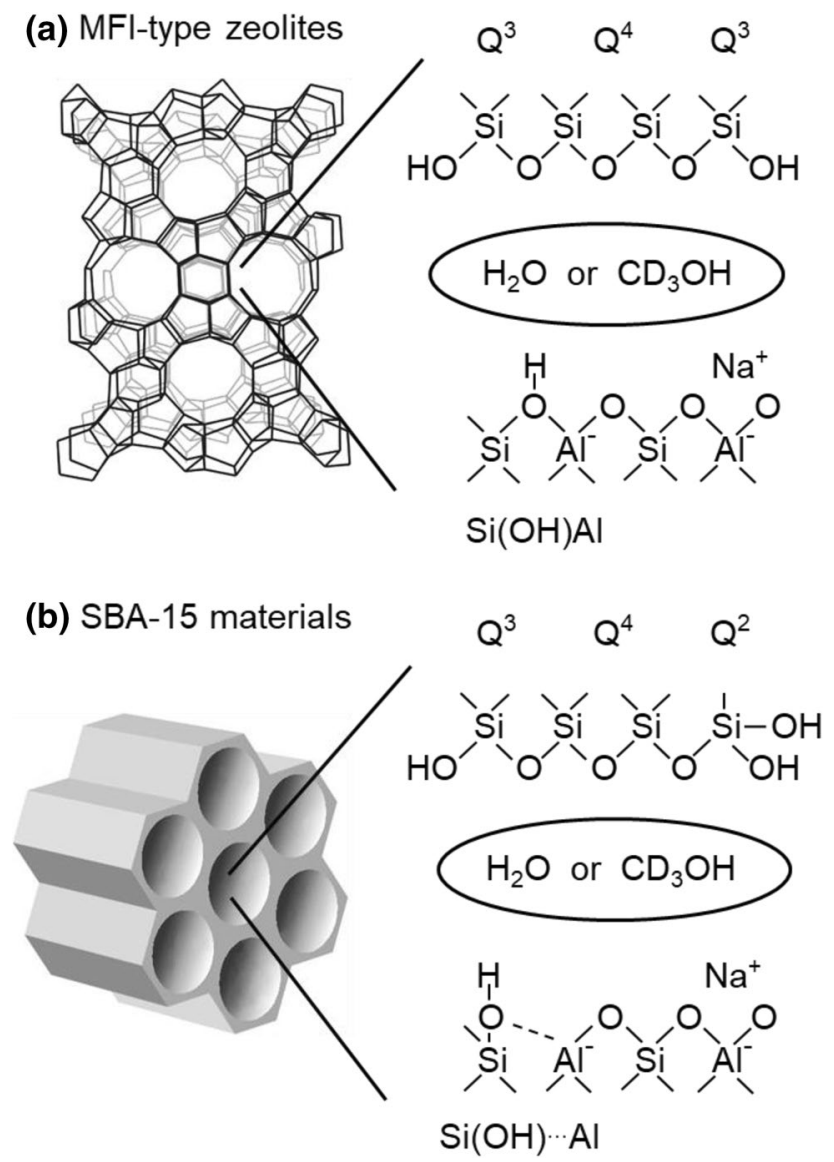

Scheme 1 Drawings of the MFI structure with 10-ring pores with a size between 0.51 and $0.56 \mathrm{~nm}$ in [100]- and [010]-direction (Baerlocher and McCusker) (a) and of long-range ordered SBA-15 with hexagonally arranged mesopores with diameters of 6.7-7.1 nm (b) on the left-hand side. Possible local structures of potential adsorption sites in the siliceous (top) and aluminum-containing state (bottom) of these materials on right-hand side as adsorption sites. By ${ }^{29} \mathrm{Si}$ solid-state NMR spectroscopy, $\mathrm{Q}^{3}$ and $\mathrm{Q}^{2}$ species can be distinguished via their chemical shifts of -100 and $-90 \mathrm{ppm}$, respectively (Engelhardt and Michel 1987). These NMR signals can be selectively enhanced via ${ }^{1} \mathrm{H} \Rightarrow{ }^{29} \mathrm{Si}$ cross polarization $(\mathrm{CP})$ experiments. In this case, a direct excitation of ${ }^{1} \mathrm{H}$ spins via a single $\pi / 2$ pulse and a subsequent polarization transfer to dipolar coupled neighbouring ${ }^{29} \mathrm{Si}$ spins is performed. The involved ${ }^{1} \mathrm{H}$ spins are, e.g., hydroxyl protons of surface $\mathrm{OH}$ groups or strongly adsorbed ${ }^{1} \mathrm{H}$-containing molecules.

In the presence of aluminum species incorporated into the framework of crystalline ZSM-5 zeolites or into the amorphous pore walls of mesoporous SBA-15 materials (Scheme 1a and b, right-hand side, bottom), adsorption sites with very different properties are present. The local structure of aluminum species in the framework of zeolites and the adsorption of molecules in the vicinity of these species have a significant influence on the quadrupole interaction of the corresponding ${ }^{27} \mathrm{Al}$ spins ( $\operatorname{spin} I=5 / 2$ ). An important parameter describing the strength of this interaction is the quadrupolar coupling constant $C_{\mathrm{q}}$, which linearly depends on the electric field gradient at the positions of the quadrupolar nuclei and, therefore, also on the presence of adsorbate molecules (Hunger and Horvath 1995; Hunger et al. 1995b). Similarly, also sodium atoms compensating the negatively charged framework aluminum $\left(\mathrm{Al}^{\mathrm{IV}}\right)$ atoms in ZSM-5 and sodium atoms in aluminummodified SBA-15 materials are involved in quadrupole interactions $\left({ }^{23} \mathrm{Na}\right.$ nuclei with spin $\left.I=3 / 2\right)$. Solid-state NMR investigations of their quadrupole interactions give useful information on the local structure and the presence of water or other molecules coordinated at these cations (Hunger et al. 1994).

Replacing the $\mathrm{Na}^{+}$cations by hydroxyl protons in ZSM-5 zeolites is accompanied by the formation of strong Brønsted acid sites [Si(OH)Al in Scheme1)], which are catalytically active and, therefore, act as strong adsorption sites. Often, their presence, quantity, and strength is investigated by adsorption of probe molecules, such as ammonia (Dyballa et al. 2018a, b; Wang et al. 2014, 2015). In aluminum-modified mesoporous materials, the incorporation of $\mathrm{Al}$ atoms into the pore walls can lead to the formation of Lewis sites in the vicinity of $\mathrm{SiOH}$ groups $[\mathrm{Si}(\mathrm{OH}) \cdots \mathrm{Al}$ in $\mathrm{Scheme} 1]$. The latter $\mathrm{SiOH}$ groups are characterized by an enhanced acid strength and their presence can be proven and quantified by adsorption of ammonia and the ${ }^{1} \mathrm{H}$ MAS NMR observation of subsequently formed $\mathrm{NH}_{4}{ }^{+}$ions (Hunger 1996; Jiang et al. 2011; Lang et al. 2017).

In the following sections, the application of the abovementioned solid-state NMR tools for the study and characterization of potential adsorption sites and their interactions with water and methanol is described. 


\subsubsection{Adsorption of water and methanol on silanol groups in silicalite- 1 and siliceous SBA-15}

3.2.1.1 Silicalite-1 Figure 1 shows the ${ }^{29} \mathrm{Si}$ CPMAS NMR spectra of Silicalite-1 (a) and siliceous SBA-15 (b), which were recorded in the calcined (desorbed $723 \mathrm{~K}$ ) state and after saturation with $\mathrm{H}_{2} \mathrm{O}$ respectively $\mathrm{CD}_{3} \mathrm{OH}$. In the case of Silicalite-1, the spectrum of the calcined sample consists of signals at -103 and -113 ppm due to $\mathrm{SiOH}$ groups of $\mathrm{Q}^{3}$ type and due to tetrahedrally coordinated framework silicon atoms of $\mathrm{Q}^{4}$ type (see Scheme 1), respectively. Upon saturation with $\mathrm{H}_{2} \mathrm{O}$, a weak decrease of these signals can be observed, which agrees with the observation of the Lercher group (Wang et al. 2019) for ${ }^{29} \mathrm{Si}$ CPMAS NMR investigation of hydrated H-ZSM-5 zeolites. In this earlier work, the strong decrease of ${ }^{29} \mathrm{Si}$ CPMAS NMR signal of silicon atoms contributing to $\mathrm{Si}(\mathrm{OH}) \mathrm{Al}$ groups for increasing water loading was explained by hydrogen transfer from the abovementioned $\mathrm{OH}$ groups to water molecules leading to the formation of hydroxonium ions. Furthermore, the spectra of these authors showed also a decrease of the $\mathrm{Q}^{3}$ signal with increasing water loading. This observation indicates that interactions of water with $\mathrm{SiOH}$ groups exist in $\mathrm{ZSM}-5$ zeolites, but in a weaker manner in comparison with $\mathrm{Si}(\mathrm{OH})$ Al groups. The decrease of the ${ }^{29} \mathrm{Si}$ CPMAS NMR signal of $\mathrm{SiOH}$ groups is explained by a decreased polarization transfer upon saturation. This is explained by an increase of the ${ }^{1} \mathrm{H}-{ }^{29} \mathrm{Si}$ distance due to an increase of the $\mathrm{O}-\mathrm{H}$ distance of the corresponding $\mathrm{SiOH}$ groups caused by $\mathrm{H}$-bondings to water molecules. In this connection it should be noted that the weak decrease of the polarization transfer also indicates that the $\mathrm{H}$ atoms of the water molecules do not contribute to the polarization transfer. Hence, their distance to next $\mathrm{Si}$ atoms is too large or the $\mathrm{H}$ atoms of adsorbed water are mobile, e.g., because they are involved in a water rotation. On the other hand, the weak intensity decrease of the ${ }^{29} \mathrm{Si}$ CPMAS NMR signals for the water-loaded Silicalite-1 (Fig. 1a), therefore, also indicates weak $\mathrm{H}_{2} \mathrm{O} / \mathrm{SiOH}$ interactions. In contrast, a much stronger decrease of the signal intensities occurred upon the saturation of Silicalite-1 with $\mathrm{CD}_{3} \mathrm{OH}\left(\mathrm{CD}_{3} \mathrm{OH}\right.$ saturated). The above-mentioned finding hints at much stronger $\mathrm{CD}_{3} \mathrm{OH} / \mathrm{SiOH}$ interactions compared with the $\mathrm{H}_{2} \mathrm{O} / \mathrm{SiOH}$ interactions for Silicalite-1.

3.2.1.2 SBA-15 The ${ }^{29} \mathrm{Si}$ CPMAS NMR spectrum of the calcined SBA-15 (desorbed $723 \mathrm{~K}$ ) consists of $\mathrm{Q}^{3}$ and $\mathrm{Q}^{2}$ signals at -101 and -92 ppm, respectively (Fig. 1b). A weak high-field shoulder at $-110 \mathrm{ppm}$ is due to $\mathrm{Q}^{4}$ species. In contrast to the finding for Silicalite-1, saturation of SBA-15 with water $\left(\mathrm{H}_{2} \mathrm{O}\right.$ saturated) led to a significant increase of the ${ }^{29} \mathrm{Si}$ CPMAS NMR signals. This effect may be due to an adsorption of water at well accessible $\mathrm{Q}^{2}$-type $\mathrm{SiOH}$ groups in such a manner that the $\mathrm{H}$ atoms of these water molecules are able to contribute to the ${ }^{1} \mathrm{H} \Rightarrow{ }^{29} \mathrm{Si}$ polarization transfer. In this case, the intensity decrease of the $\mathrm{Q}^{2}$ signals of $\mathrm{SiOH}$ groups involved in $\mathrm{H}$-bondings to water molecules is overcompensated by the contribution of the additional ${ }^{1} \mathrm{H}$ spins of the adsorbed water molecules to the ${ }^{1} \mathrm{H} \Rightarrow{ }^{29} \mathrm{Si}$ polarization transfer. This effect cannot occur for Silicalite-1 since this material has no $\mathrm{Q}^{2}$-type $\mathrm{SiOH}$ groups. These water molecules must be adsorbed at the two neighbouring $\mathrm{SiOH}$ groups $\left(\mathrm{Q}^{2}\right)$ in such a manner that their $\mathrm{H}$ atoms are not mobile and have a short distance to next nearest $\mathrm{Si}$ atoms. The ${ }^{29} \mathrm{Si}$ CPMAS NMR spectrum of SBA-15 saturated with $\mathrm{CD}_{3} \mathrm{OH}\left(\mathrm{CD}_{3} \mathrm{OH}\right.$ saturated), on the other hand, shows significantly lower signal intensities compared with the spec-
Fig. $1{ }^{29} \mathrm{Si} \mathrm{CPMAS} \mathrm{NMR} \mathrm{spec-}$ tra of Silicalite-1 (a) and siliceous SBA-15 (b) recorded in the calcined state (desorbed at $723 \mathrm{~K}$ ) and after saturating calcined samples with water $\left(\mathrm{H}_{2} \mathrm{O}\right.$ saturated) or methanol $\left(\mathrm{CD}_{3} \mathrm{OH}\right.$ saturated)
${ }^{29} \mathrm{Si}$ CPMAS NMR

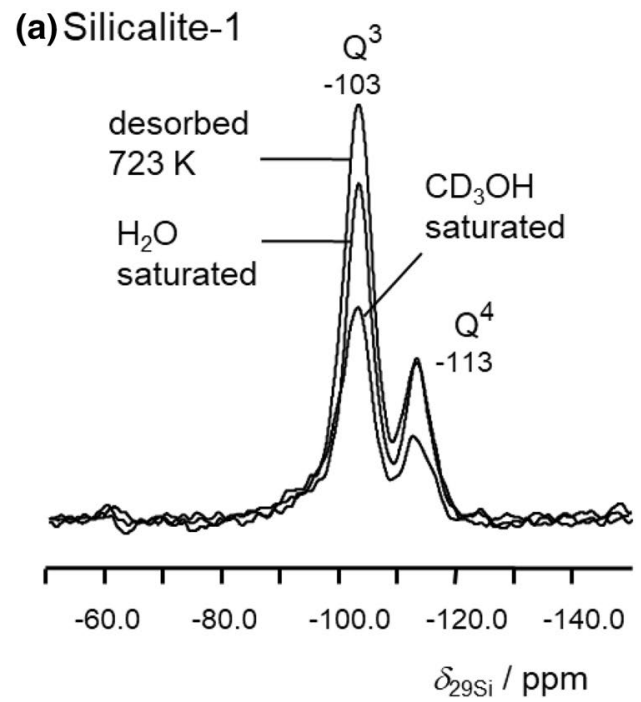

${ }^{29}$ Si CPMAS NMR

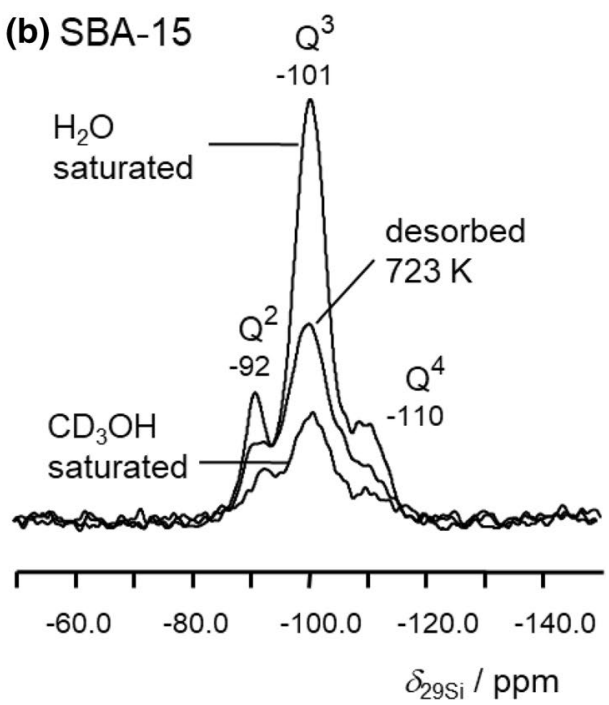


trum of calcined SBA-15, which is similar to the finding for methanol-loaded Silicalite-1. Also for SBA-15, therefore, strong $\mathrm{CD}_{3} \mathrm{OH} / \mathrm{SiOH}$ interactions can be assumed, leading to an increase of the ${ }^{1} \mathrm{H}-{ }^{29} \mathrm{Si}$ distance due to an increase of the $\mathrm{O}-\mathrm{H}$ distance of the corresponding $\mathrm{OH}$ groups caused by $\mathrm{H}$-bondings to methanol molecules.

\subsubsection{Adsorption of water and methanol on sodium and aluminum species in Na-ZSM-5 and Na-[AI] SBA-15}

3.2.2.1 Water adsorption The ${ }^{23} \mathrm{Na}$ MAS NMR spectra of Na-ZSM-5 and Na-[Al]SBA-15 in different hydration/dehydration states are shown in Fig. 2a and c. The ${ }^{23} \mathrm{Na}$ MAS NMR signal of the calcined Na-ZSM-5 (desorbed $723 \mathrm{~K}$ ) occurs at ca. $-24 \mathrm{ppm}$ and its broadening can be explained by a quadrupole tensor corresponding to a coupling constant of $C_{\mathrm{q}}=2.2 \pm 0.2 \mathrm{MHz}$ and at an isotropic chemical shift of $-6 \mathrm{ppm}$. This $C_{\mathrm{q}}$ value agrees well with $C_{\mathrm{q}}=2.0 \mathrm{MHz}$ published in an earlier work (Hunger et al. 1997b). The difference between the experimentally observed chemical shift of ca. $-24 \mathrm{ppm}$ and the above-mentioned isotropic chemical shift of $-6 \mathrm{ppm}$, the latter obtained by computer simulation, is due to the second-order quadrupolar shift, which is also proportional to the strength of the quadrupole interaction. Therefore, the shift of the experimentally observed ${ }^{23} \mathrm{Na}$ MAS NMR signal from $-24 \mathrm{ppm}$ for the calcined sample to $-4 \mathrm{ppm}$ for the fully hydrated sample $\left(\mathrm{H}_{2} \mathrm{O}\right.$ saturated $)$ hints at a significant decrease of the electric field gradient at the $\mathrm{Na}^{+}$cations due to adsorption of water molecules. The broadening of the signal at $-4 \mathrm{ppm}$ corresponds to a small $C_{\mathrm{q}}$ value of $<0.1 \mathrm{MHz}$. Evacuation of the hydrated NaZSM-5 at $373 \mathrm{~K}$ (desorbed $373 \mathrm{~K}$ ) led to a resonance shift of the ${ }^{23} \mathrm{Na}$ MAS NMR signal from $-4 \mathrm{ppm}$ to the experimentally observed value of $-20 \mathrm{ppm}$, i.e. not to the shift of ca. $-24 \mathrm{ppm}$ observed for the completely dehydrated material. This finding indicates that the residual water molecules remaining on Na-ZSM-5 after evacuation at $373 \mathrm{~K}$ are adsorbed at $\mathrm{Na}^{+}$cations.

The ${ }^{27}$ Al MAS NMR spectra of Na-ZSM-5 and Na-[Al] SBA-15 in different hydration/dehydration states are shown in Fig. $2 b$ and d. The ${ }^{27}$ Al MAS NMR signal of the calcined
Fig. $2{ }^{23} \mathrm{Na}$ MAS NMR (lefthand side) and ${ }^{27} \mathrm{Al}$ MAS NMR spectra (right-hand side) of $\mathrm{Na}-$ ZSM-5 (a, b) and Na-[Al]SBA$15(\mathbf{c}, \mathbf{d})$ recorded after saturating calcined samples with water $\left(\mathrm{H}_{2} \mathrm{O}\right.$ saturated), after desorption of water at $373 \mathrm{~K}$ (desorbed at $373 \mathrm{~K}$ ), and in the calcined state (desorbed at $723 \mathrm{~K}$ ). The chemical shift values are the experimentally observed shift values of the signal maxima
${ }^{23} \mathrm{Na}$ MAS NMR

(a) Na-ZSM-5

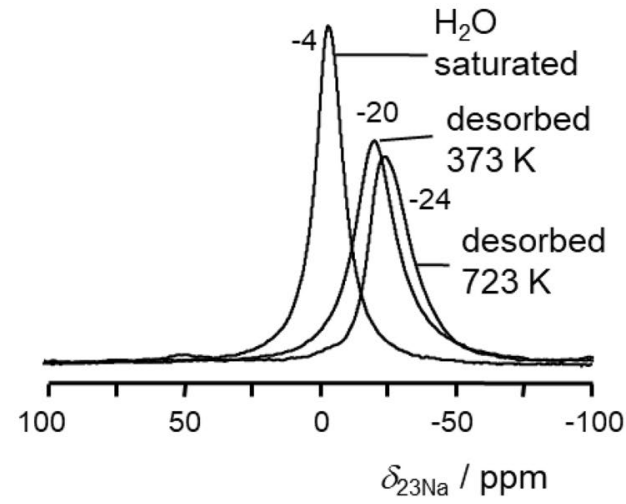

${ }^{23} \mathrm{Na}$ MAS NMR

(c) $\mathrm{Na}-[\mathrm{Al}] \mathrm{SBA}-15$

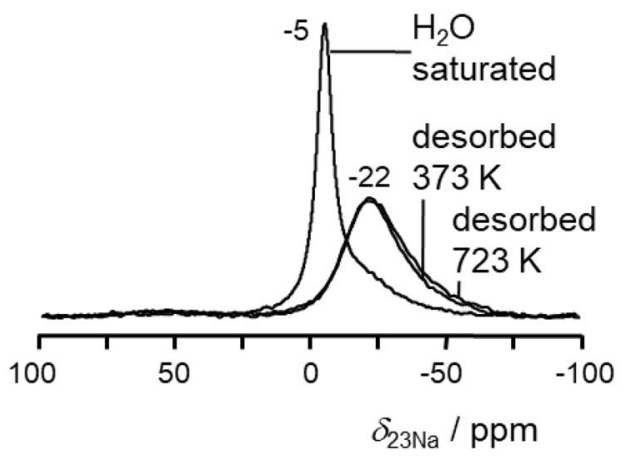

${ }^{27}$ AI MAS NMR

(b) Na-ZSM-5

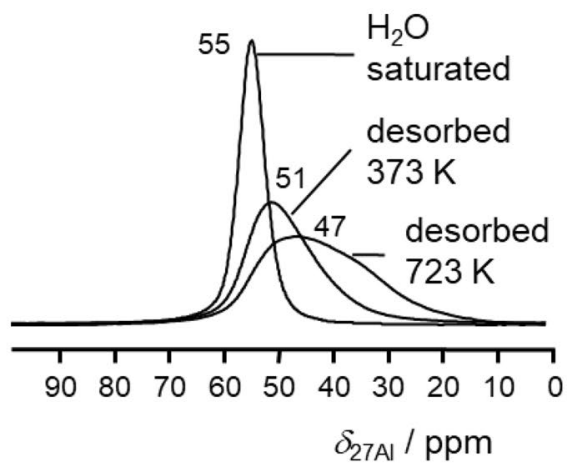

${ }^{27}$ AI MAS NMR

(d) $\mathrm{Na}-[\mathrm{Al}] \mathrm{SBA}-15$

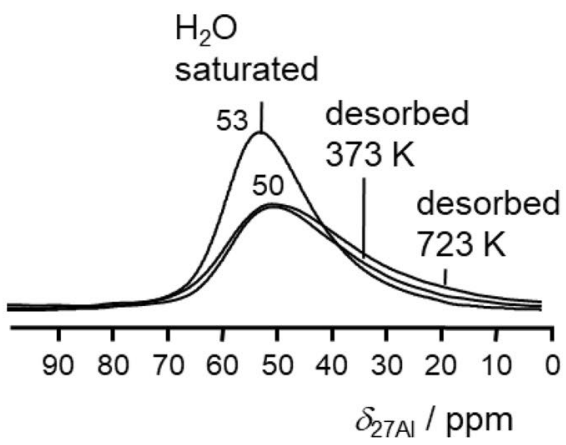


Na-ZSM-5 occurs at ca. $47 \mathrm{ppm}$ and its broadening corresponds to a quadrupole tensor with a coupling constant of $C_{\mathrm{q}}=4.5 \pm 0.2 \mathrm{MHz}$ and at an isotropic chemical shift of $55 \mathrm{ppm}$. This $C_{\mathrm{q}}$ value agrees well with $C_{\mathrm{q}}=4.7 \mathrm{MHz}$ published in an earlier work of Freude et al. (Freude et al. 1994) The isotropic shift value of $55 \mathrm{ppm}$ is typical for aluminum species in a tetrahedral oxygen coordination, i.e. at framework aluminum of the ZSM-5 lattice (Engelhardt and Michel 1987). Like for ${ }^{23} \mathrm{Na}$ nuclei, the different experimentally observed resonance positions of the ${ }^{27} \mathrm{Al}$ MAS NMR signals for Na-ZSM-5 with difference water contents are due to the second-order quadrupolar shift, i.e. a different strength of the quadrupole interaction. Consequently, the broadening of the ${ }^{27} \mathrm{Al}$ MAS NMR signal of the hydrated Na-ZSM-5 corresponds to $C_{\mathrm{q}}=0.8 \pm 0.2 \mathrm{MHz}$, which is much less than the $C_{\mathrm{q}}$ value of $4.5 \mathrm{MHz}$ for the calcined material (vide supra). In this connection it must be noted that the adsorption of water on Na-ZSM-5 and subsequent desorption is not accompanied by a change of the isotropic shift value of the framework aluminum species at $55 \mathrm{ppm}$. Hence, no change of the oxygen coordination occurs, i.e. there is no direct coordination of water at these aluminum species. Since the negatively charge framework aluminum atoms and the $\mathrm{Na}^{+}$cations act as ion pairs $\left(\mathrm{Na}^{+} /\left(\mathrm{Al}^{\mathrm{IV}}\right)^{-}\right)$, the water-induced changes of the ${ }^{27} \mathrm{Al}$ MAS NMR spectroscopic parameters are caused by the water coordination at the directly neighboured $\mathrm{Na}^{+}$cations.

The ${ }^{23} \mathrm{Na}$ MAS NMR spectra of Na-[Al]SBA-15 in the different hydration/dehydration states (Fig. 2c) are similar to these of Na-ZSM-5 (Fig. 2a). For Na-[Al]SBA-15, the resonance shift from $-22 \mathrm{ppm}$ for the calcined material to $-5 \mathrm{ppm}$ for the fully hydrated material indicates an adsorption of water molecules at the sodium species leading to a strong decrease of the electric field gradient at their position. In contrast to Na-ZSM-5, however, there is only a very weak difference between the ${ }^{23} \mathrm{Na}$ MAS NMR signals of Na-[Al] SBA-15 upon desorption at $373 \mathrm{~K}$ and $723 \mathrm{~K}$. Hence, only few water molecules remain at the sodium species of $\mathrm{Na}$ [Al]SBA-15 after the desorption at $373 \mathrm{~K}$. A similar effect occurs for the ${ }^{27} \mathrm{Al}$ MAS NMR spectra of Na-[Al]SBA-15 differently loaded with water in Fig. 2d. Also in these spectra, a very weak difference between the ${ }^{27}$ Al MAS NMR signals of Na-[Al]SBA-15 upon desorption at $373 \mathrm{~K}$ and $723 \mathrm{~K}$ was found, which corresponds to a weak influence of the remaining water molecules at neighbouring sodium species.

3.2.2.2 Methanol adsorption The ${ }^{23} \mathrm{Na}$ MAS NMR spectra of Na-ZSM-5 and Na-[Al]SBA-15 in different states of methanol sorption are shown in Fig. $3 \mathrm{a}$ and c. The ${ }^{23} \mathrm{Na}$ MAS NMR signal of the fully $\mathrm{CD}_{3} \mathrm{OH}$-loaded Na-ZSM-5 occurs at $-12 \mathrm{ppm}$ and its broadening can be explained by a quadrupole tensor with a coupling constant of $C_{\mathrm{q}}=1.4 \pm 0.2 \mathrm{MHz}$ and at an isotropic chemical shift of -
$5 \mathrm{ppm}$. The comparison with the calcined Na-ZSM-5 (desorbed at $723 \mathrm{~K}$ ) with the $C_{\mathrm{q}}$ value of $2.2 \mathrm{MHz}$ indicates that also methanol is adsorbed at the $\mathrm{Na}^{+}$cations accompanied by a significant decrease of the electric field gradient and, therefore, of the quadrupolar coupling constant. For methanol adsorption on Na-ZSM-5, however, this effect is not as strong as found for water adsorption, which decreased the $C_{\mathrm{q}}$ value from 2.2 to $<0.1 \mathrm{MHz}$ (vide supra). Upon desorption of methanol at $373 \mathrm{~K}$, a resonance shift to an experimentally observed chemical shift value of -21 ppm occurs, which is again higher than that of the fully desorbed sample of -24 ppm (Fig. 3a). As discussed for water desorption at $373 \mathrm{~K}$, this above-mentioned shift difference hints at a coordination of the remaining methanol molecules at $\mathrm{Na}^{+}$cations. Similarly, the ${ }^{27} \mathrm{Al}$ MAS NMR spectra of NaZSM-5 with different methanol loadings in Fig. 3b shows signals of tetrahedrally coordinated framework aluminum species with different second-order quadrupolar shifts. As found for water adsorption, also the methanol adsorption causes a decrease of the quadrupolar coupling constant from $C_{\mathrm{q}}=2.2 \mathrm{MHz}$ (signal at $47 \mathrm{ppm}$ ) for the calcined Na-ZSM-5 to $C_{\mathrm{q}}=1.6 \pm 0.2 \mathrm{MHz}$ (signal at $53 \mathrm{ppm}$ ) for the fully methanol-loaded material. Again, no change of the oxygen coordination of the aluminum species occurred as indicated by the unchanged isotropic chemical shift value of $55 \mathrm{ppm}$. Hence, also methanol is preferentially adsorbed at the $\mathrm{Na}^{+}$cations of Na-ZSM-5, which induces a decrease of the electric field gradient at neighbouring framework aluminum species acting as ion pairs $\left(\mathrm{Na}^{+} /\left(\mathrm{Al}^{\mathrm{IV}}\right)^{-}\right)$.

The ${ }^{23} \mathrm{Na}$ MAS NMR spectra of Na-[Al]SBA-15 in different states of methanol sorption in Fig. $3 \mathrm{c}$ are similar to those found for Na-ZSM-5 in Fig. 3a. The most important difference between the ${ }^{23} \mathrm{Na}$ MAS NMR spectra of these two materials loaded with methanol is the even stronger overlap of the signals recorded after methanol desorption from Na-[Al]SBA-15 at $373 \mathrm{~K}$ and $723 \mathrm{~K}$ (Fig. 3c). Hence, upon methanol desorption at $373 \mathrm{~K}$, no methanol molecules remain at the sodium species in Na-[Al]SBA-15, which may be caused by their interaction with other adsorption sites or due to their too low number. Similarly, also the ${ }^{27} \mathrm{Al}$ MAS NMR spectra of Na-[Al]SBA-15 loaded with methanol show no difference between the signals recorded upon desorption at $373 \mathrm{~K}$ and $723 \mathrm{~K}$ (Fig. 3d). Hence, no effect of methanol molecules remaining upon the desorption at $373 \mathrm{~K}$ occurs at the sodium or the aluminum species of Na-[Al]SBA-15.

\subsubsection{Investigation of Brønsted acid sites in H-ZSM-5 and $\mathrm{H}-[\mathrm{Al}] \mathrm{SBA}-15$}

The ${ }^{1} \mathrm{H}$ MAS NMR spectrum of the calcined H-ZSM-5 in Fig. 5a, bottom, consists of the signals of $\mathrm{SiOH}$ groups at $2.0 \mathrm{ppm}$ and $\mathrm{Br} \varnothing \mathrm{nsted}$ acidic bridging $\mathrm{OH}$ groups ( $\mathrm{Si}(\mathrm{OH}) \mathrm{Al})$ at $4.1 \mathrm{ppm}$ (Hunger 1997; Jiang et al. 2011). 
Fig. $3{ }^{23} \mathrm{Na}$ MAS NMR (lefthand side) and ${ }^{27} \mathrm{Al}$ MAS NMR spectra (right-hand side) of Na-ZSM-5 (a, b) and Na-[Al] SBA-15 (c, d) recorded after saturating calcined samples with methanol $\left(\mathrm{CD}_{3} \mathrm{OH}\right.$ saturated), after desorption of methanol at $373 \mathrm{~K}$ (desorbed at $373 \mathrm{~K}$ ), and in the calcined state (desorbed at $723 \mathrm{~K}$ ). The chemical shifts are the experimentally observed values of the signal maxima
${ }^{23} \mathrm{Na}$ MAS NMR

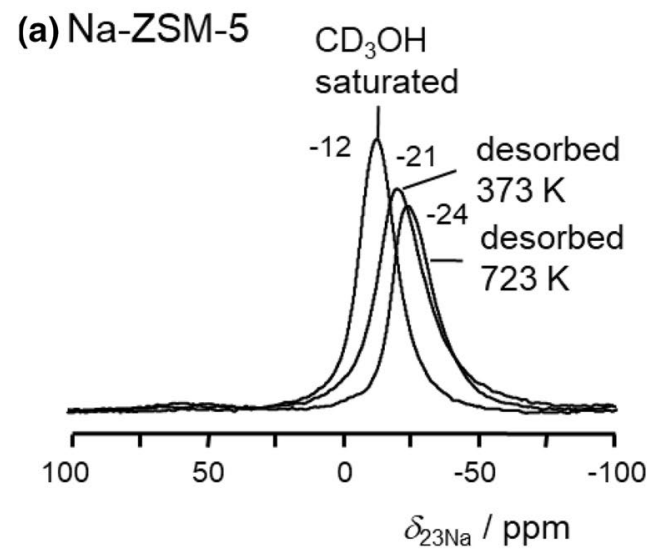

\section{${ }^{23} \mathrm{Na}$ MAS NMR}

(c) $\mathrm{Na}-[\mathrm{Al}] \mathrm{SBA}-15$

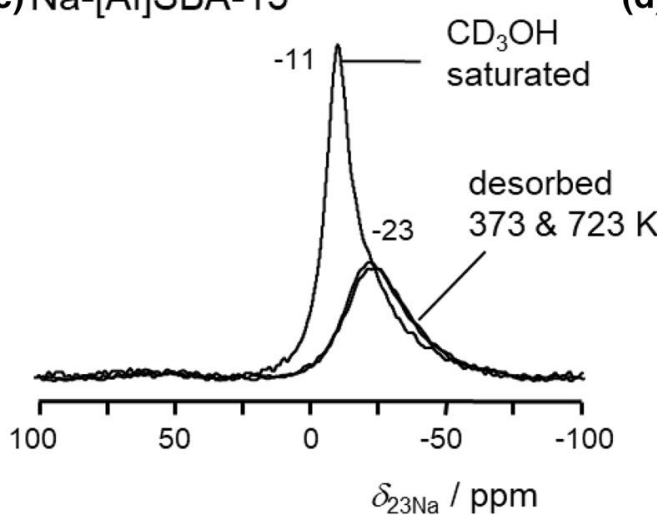

${ }^{27} \mathrm{AI}$ MAS NMR

(b) Na-ZSM-5

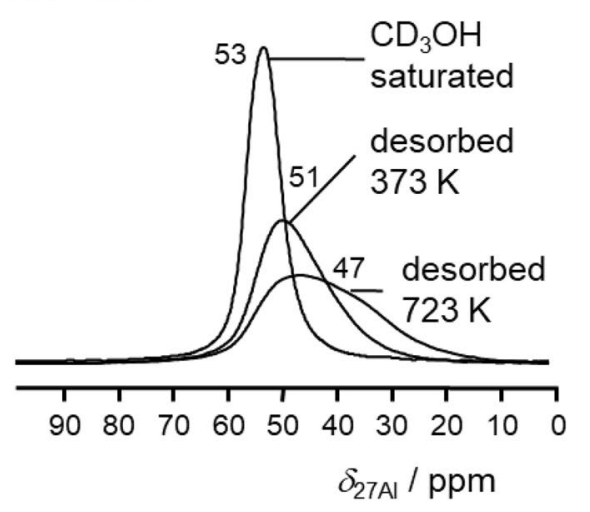

${ }^{27} \mathrm{AI}$ MAS NMR

(d) $\mathrm{Na}-[\mathrm{Al}] \mathrm{SBA}-15$

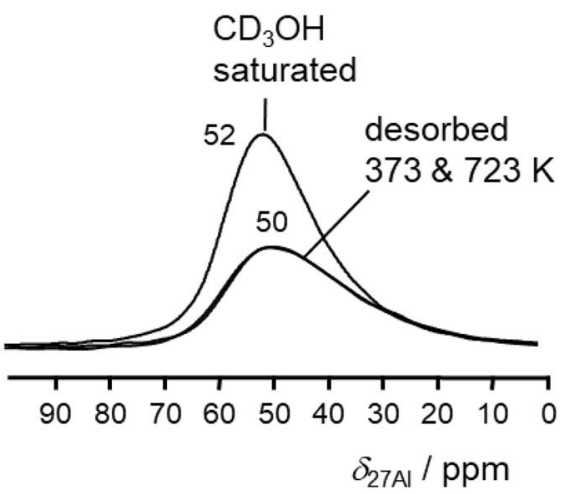

Upon adsorption of ammonia on H-ZSM-5, a new signal at $6.7 \mathrm{ppm}$ due to $\mathrm{NH}_{4}{ }^{+}$ions occurred (Fig. 4a, top). The intensity of this signal corresponds to the formation of $0.49 \pm 0.02 \mathrm{mmol} / \mathrm{g}$ ammonium ions at a same number of Brønsted acidic bridging $\mathrm{OH}$ groups [ $\mathrm{Si}(\mathrm{OH}) \mathrm{Al}]$. This value is slightly lower than the total number of aluminum species of $0.60 \mathrm{mmol} / \mathrm{g}$ determined by ICP-OES, due to the formation of aluminum species that do not contribute to the acidity. According to Haase and Sauer $(1994,1995)$ the abovementioned $\mathrm{Si}(\mathrm{OH}) \mathrm{Al}$ groups are able to protonate both water and methanol.

The ${ }^{1} \mathrm{H}$ MAS NMR spectrum of calcined H-[Al]SBA-15 in Fig. 4b, bottom, consists of a single signal at $1.8 \mathrm{ppm}$ due to $\mathrm{SiOH}$ groups. Despite the modification of this SBA15 with aluminum, no additional signal due to Brønsted acidic $\mathrm{OH}$ groups can be observed in the low-field range. The weak low-field tailing of the signal at $1.8 \mathrm{ppm}$ is often assigned to H-bonded SiOH groups (Jiang et al. 2011). On the other hand, the ammonium signal at $6.7 \mathrm{ppm}$, occurring after ammonia adsorption, hints at the presence of $\mathrm{SiOH}$ with enhanced Brønsted acidity. The intensity of this signal corresponds to $0.18 \mathrm{mmol} / \mathrm{g}$ ammonium ions formed at a same number of Brønsted acidic $\mathrm{OH}$ groups. Hence, $16 \%$ of the total number of aluminum atoms are incorporated into the SBA-15 framework in such a manner that they act as strong Lewis sites in the direct vicinity of $\mathrm{SiOH}$ groups $(\mathrm{Si}(\mathrm{OH}) \cdots \mathrm{Al})$, causing an enhancement of their Brønsted acid strength. These $\mathrm{Si}(\mathrm{OH}) \cdots \mathrm{Al}$ occurring in [Al]SBA-15 are able to protonate strongly basic probe molecules, such as observed for aluminum-modified MCM-41 (Hunger et al. 1999; Wang et al. 2013a; Xu et al. 2002) and aluminummodified silica prepared by flame spray pyrolysis (Huang et al. 2010; Wang et al. 2013b, 2020).

In addition to the Lewis acidic framework aluminum species in [Al]SBA-15, a high content of the aluminum atoms must be incorporated into the pore walls of SBA-15 in such a manner that they are tetrahedrally coordinated $\left(\mathrm{Al}^{\mathrm{IV}}\right)$, as indicated by the ${ }^{27} \mathrm{Al}$ MAS NMR spectra in Figure S3, but in the direct vicinity of $\mathrm{SiOH}$ groups. Since these $\mathrm{Al}^{\mathrm{IV}}$ species do not cause Brønsted sites with an acid strength suitable for the protonation of ammonia, they must be incorporated in a larger distance to $\mathrm{SiOH}$ groups compared with 


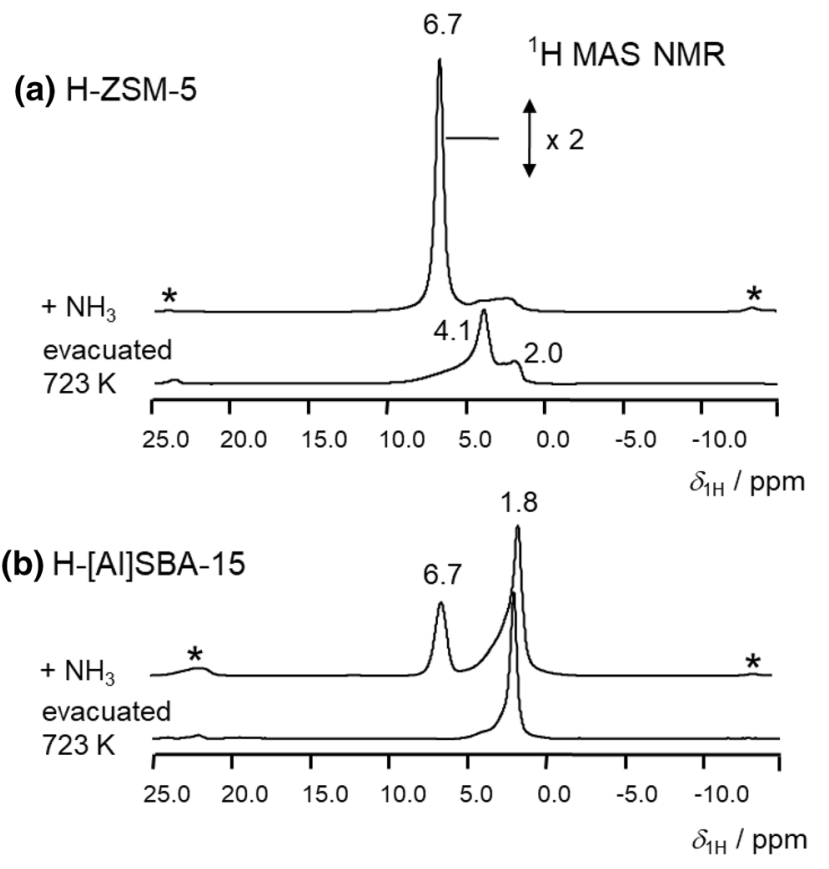

Fig. $4{ }^{1} \mathrm{H}$ MAS NMR spectra of H-ZSM-5 (a) and H-[Al]SBA-15 (b) recorded in the calcined state (evacuated at $723 \mathrm{~K}$ ) and after adsorption of ammonia and subsequent desorption at $453 \mathrm{~K}$ for $2 \mathrm{~h}$ (top)

the above-mentioned Lewis acidic framework aluminum atoms. Due to their large distance to $\mathrm{SiOH}$ groups, only a weak influence on the properties of these hydroxyl groups is expected. Finally, it should be noted that no ammonium formation was observed upon ammonia adsorption on calcined Na-ZSM-5 and Na-[Al]SBA-15 (not shown). Thus, both materials are, in agreement with ICP-OES measurements, in pure Na-form. Summarizing, the ${ }^{1} \mathrm{H}$ MAS NMR studies of ammonia-loaded samples have shown that the Na-form materials contain no Brønsted acid sites. While H-ZSM-5 contain a number of Brønsted acid sites similar to the number of aluminum atoms in this material, only $16 \%$ of aluminum atoms in $\mathrm{H}-[\mathrm{Al}] \mathrm{SBA}-15$ contribute to the formation of Brønsted acid sites.

\subsection{Study of water and methanol adsorption on MFI-type zeolites}

\subsubsection{Silicalite-1}

For our Silicalite-1, the desorption enthalpy of $\Delta H=38 \mathrm{~kJ} /$ mol, determined for desorption of water from the fully hydrated Silicalite-1 (Table 2, column 2), is close to the evaporation heat of liquid water of $41 \mathrm{~kJ} / \mathrm{mol}$ (Flanigen et al. 1978). This finding indicates that water mainly exist as bulk clusters, which is in good accordance with the weak $\mathrm{H}_{2} \mathrm{O}$ / $\mathrm{SiOH}$ interactions observed for this sample by ${ }^{29} \mathrm{Si}$ CPMAS NMR spectroscopy (Sect. 3.2.1). In literature, lower values of 10 to $25 \mathrm{~kJ} / \mathrm{mol}$ were published (Flanigen et al. 1978; Sauer 1985; Zhang et al. 2012), however, for loading of few $\mathrm{H}_{2} \mathrm{O}$ molecules per $\mathrm{SiOH}$ group, i.e. if $\mathrm{H}_{2} \mathrm{O} / \mathrm{SiOH}$ interactions are dominating and no water bulk clusters exist. For the remaining water after evacuation of hydrated Silicalite- 1 at $373 \mathrm{~K}$, no $\Delta H$ value could be determined in the present work because of the low number of $0.1 \mathrm{mmol} / \mathrm{g}$ remaining water molecules (Table 2, column 3). The desorption enthalpy of $\Delta H=39 \mathrm{~kJ} / \mathrm{mol}$ for the fully methanol-loaded Silicalite-1 (Table 3, column 2) agrees very well with literature values of $43-53 \mathrm{~kJ} / \mathrm{mol}$ (Thamm 1989) and also with the evaporation heat of liquid methanol of $37 \mathrm{~kJ} / \mathrm{mol}$ (Schmeling and Strey 1983). Hence, for high methanol loadings on Silicalite-1, a major part of the methanol is in the form of bulk clusters. Interestingly, for the adsorption equilibrium at room temperature, a much higher total (weakly adsorbed plus strongly bound) loading of methanol of $1.8 \mathrm{mmol} / \mathrm{g}$ compared with water of $0.5 \mathrm{mmol} / \mathrm{g}$ was determined (Tables 2 and 3, column 3). This tendency agrees with the stronger $\mathrm{CD}_{3} \mathrm{OH} /$ $\mathrm{SiOH}$ interactions compared with $\mathrm{H}_{2} \mathrm{O} / \mathrm{SiOH}$ interactions described in Sect. 3.2.1, which supports the hydrophobic properties of Silicalite-1. After desorption at $373 \mathrm{~K}$, loadings of $0.1 \mathrm{mmol} / \mathrm{g}$ methanol were determined on Silicalite-1. Thus, like for water, no $\Delta H$ value could be determined.

The ${ }^{1} \mathrm{H}$ MAS NMR spectra of both the fully water- and methanol-loaded Silicalite-1 are shown in Figs. 5a and 6a, respectively. Both spectra reflect the similarities already observed in the ${ }^{29} \mathrm{Si}$ CPMAS NMR spectra in Fig. 1 and show strong signals at 3.7 to $3.9 \mathrm{ppm}$ with weak low-field shoulders at $6 \mathrm{ppm}$. The shift values and the small line widths of the former signals (see Tables 2 and 3, column 4), indicate that these signals are due to mobile clusters of these molecules inside the pores. Such bulk clusters of water form usually in small structural units, like the sodalite cages of SAPO-37 (Kalantzopoulos et al. 2020). The low-field shift of the latter signals and their large line widths hint at the presence of $\mathrm{H}$-bonded adsorbate clusters interacting with $\mathrm{SiOH}$ groups $\left(\left(\mathrm{H}_{2} \mathrm{O}\right)_{\mathrm{n}} / \mathrm{SiOH}\right.$ and $\left.\left(\mathrm{CD}_{3} \mathrm{OH}\right)_{\mathrm{n}} / \mathrm{SiOH}\right)$, which is supported by the findings described in Sect. 3.2.1. After desorption at $373 \mathrm{~K}$, the ${ }^{1} \mathrm{H}$ MAS NMR spectra contain only very weak signals of physisorbed water and methanol at 4.5 and $4 \mathrm{ppm}$, respectively. The very weak and narrow signals at $6.5 \mathrm{ppm}$ were already described in literature (Hunger et al. 1991) for strongly adsorbed water at defect sites in MFI-type materials, which is probably also valid for strongly adsorbed methanol at the same support.

\subsubsection{Na-ZSM-5}

At the adsorption equilibrium at room temperature, the presence of $\mathrm{Na}^{+}$cations in Na-ZSM-5 is accompanied by a higher total water and methanol loadings of $3.5 \mathrm{mmol} / \mathrm{g}$ and of $2.1 \mathrm{mmol} / \mathrm{g}$, respectively, compared to purely 
Table 2 Water desorption enthalpies $\Delta H$, determined by TGA-DSC, amounts of adsorbed water, ${ }^{1} \mathrm{H}$ MAS NMR spectroscopic parameters (chemical shift $\delta_{1 \mathrm{H}}$, line width $\Delta v_{1 / 2}$, 'w' indicates weak signals), and adsorbate assignments for the MFI-type zeolites under study investigated after desorption at temperatures of 295 to $373 \mathrm{~K}, 373$ to $723 \mathrm{~K}$, and at $723 \mathrm{~K}$

\begin{tabular}{|c|c|c|c|c|}
\hline Porous support and adsorbed species & $\Delta H \mathrm{in} \mathrm{kJ} / \mathrm{mol}$ & $\begin{array}{l}\mathrm{H}_{2} \mathrm{O} \text { or } \mathrm{OH} \\
\text { in } \mathrm{mmol} / \mathrm{g}^{\mathrm{d}}\end{array}$ & $\begin{array}{l}{ }^{1} \mathrm{H} \text { MAS NMR } \delta_{1 \mathrm{H}} \\
\text { in } \mathrm{ppm} / \Delta v_{1 / 2} \text { in } \mathrm{Hz}\end{array}$ & Assignments and references \\
\hline \multicolumn{5}{|l|}{ Silicalite-1 } \\
\hline Weakly adsorbed $\mathrm{H}_{2} \mathrm{O}^{\mathrm{a}}$ & 38 & 0.4 & $\begin{array}{l}3.9 / 600 \\
\text { ca. } 6 / 1700\end{array}$ & $\begin{array}{l}\text { Mobile } \mathrm{H}_{2} \mathrm{O} \text { cluster (Batamack et al. 1991) } \\
\left(\mathrm{H}_{2} \mathrm{O}\right)_{\mathrm{n}} / \mathrm{SiOH} \text { (Grünberg et al. 2004) }\end{array}$ \\
\hline Strongly bound $\mathrm{H}_{2} \mathrm{O}^{\mathrm{b}}$ & n.d. ${ }^{\mathrm{e}}$ & 0.1 & $\begin{array}{l}\text { ca. } 4.5 / 2000 \\
6.5 \mathrm{w} / 180\end{array}$ & $\begin{array}{l}\mathrm{H}_{2} \mathrm{O} / \mathrm{SiOH} \text { (Grünberg et al. 2004) } \\
\mathrm{H}_{2} \mathrm{O} / \text { defect sites (Hunger et al. 1991) }\end{array}$ \\
\hline Pure $\mathrm{OH}^{\mathrm{c}}$ & - & 0.3 & $\begin{array}{l}1.8 / 200 \\
\text { ca. } 4 \mathrm{w} / 1500\end{array}$ & $\begin{array}{l}\text { SiOH (Jiang et al. 2011) } \\
\text { H-bonded SiOH (Jiang et al. 2011) }\end{array}$ \\
\hline \multicolumn{5}{|l|}{ Na-ZSM-5 } \\
\hline Weakly adsorbed $\mathrm{H}_{2} \mathrm{O}^{\mathrm{a}}$ & 27 & 3.1 & $3.2 / 500$ & $\left(\mathrm{H}_{2} \mathrm{O}\right)_{\mathrm{n}} / \mathrm{Na}^{+}$(Kasai and Jones 1984) \\
\hline Strongly bound $\mathrm{H}_{2} \mathrm{O}^{\mathrm{b}}$ & 66 & 0.4 & $2.6 / 2000$ & $\mathrm{H}_{2} \mathrm{O} / \mathrm{Na}^{+}$(Kasai and Jones 1984) \\
\hline Pure $\mathrm{OH}^{\mathrm{c}}$ & - & 0.1 & $\begin{array}{l}1.8 / 200 \\
\text { ca. } 3 \mathrm{w} / 400\end{array}$ & $\begin{array}{l}\text { SiOH (Hunger et al. 1996; Jiang et al. 2011) } \\
\text { H-bonded SiOH (Hunger et al. 1996; Jiang et al. 2011) }\end{array}$ \\
\hline \multicolumn{5}{|l|}{ H-ZSM-5 } \\
\hline Weakly adsorbed $\mathrm{H}_{2} \mathrm{O}^{\mathrm{a}}$ & 31 & 2.9 & $5.9 / 1100$ & $\begin{array}{l}\left(\mathrm{H}_{2} \mathrm{O}\right)_{\mathrm{n}} / \mathrm{Si}(\mathrm{OH}) \mathrm{Al} \text { (Batamack et al. 1991; Hunger et al. } \\
1991)\end{array}$ \\
\hline Strongly bound $\mathrm{H}_{2} \mathrm{O}^{\mathrm{b}}$ & 63 & 0.3 & $\begin{array}{l}3.0 / 1000 \\
\text { ca. } 6 / 2400 \\
6.5 \mathrm{w} / 200\end{array}$ & $\begin{array}{l}\mathrm{H}_{2} \mathrm{O} / \mathrm{SiOH} \text { (Grünberg et al. 2004) } \\
\mathrm{H}_{2} \mathrm{O} / \mathrm{Si}(\mathrm{OH}) \mathrm{Al} \text { (Batamack et al. 1991; Hunger et al. } \\
\text { 1991) } \\
\mathrm{H}_{2} \mathrm{O} / \text { defect sites (Hunger et al. 1991) }\end{array}$ \\
\hline Pure $\mathrm{OH}^{\mathrm{c}}$ & - & 0.6 & $\begin{array}{l}1.8 / 200 \\
\text { ca. } 3 \mathrm{w} / 400 \\
4.0 / 400 \\
5.3 / 1400\end{array}$ & $\begin{array}{l}\text { SiOH (Jiang et al. 2011) } \\
\text { H-bonded SiOH (Jiang et al. 2011) } \\
\text { Si(OH)Al (Hunger et al. 1996; Jiang et al. 2011) } \\
\text { disturbed Si(OH)Al (Hunger et al. 1996; Jiang et al. } \\
\text { 2011) }\end{array}$ \\
\hline
\end{tabular}

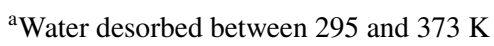

${ }^{\mathrm{b}}$ Water desorbed between 373 and $723 \mathrm{~K}$

${ }^{\mathrm{c}}$ Hydroxyl groups determined after evacuation at $723 \mathrm{~K}$

${ }^{\mathrm{d}}$ Determined by ${ }^{1} \mathrm{H}$ MAS NMR spectroscopy using an external intensity standard

e Not determined

siliceous material (Tables 2 and 3). The ratio of these adsorbate loadings is thereby reverse to those of Silicalite-1 ( 0.5 and $1.8 \mathrm{mmol} / \mathrm{g}$, respectively) under equivalent conditions. Hence, Na-ZSM-5 is more a hydrophilic and less an organophilic support material, in contrast to Silicalite-1. The low desorption enthalpy of $\Delta H=27 \mathrm{~kJ} /$ mol (Table 2, column 2) for the weakly adsorbed water indicates that these molecules do not exist as bulk clusters, like in Silicalite-1 $(\Delta H=38 \mathrm{~kJ} / \mathrm{mol})$. As supported by the solid-state NMR studies described in Sect. 3.2.2., water molecules are preferentially adsorbed at the $\mathrm{Na}^{+}$cations of Na-ZMS-5 in form of hydration shells around the cation $\left(\left(\mathrm{H}_{2} \mathrm{O}\right)_{\mathrm{n}} / \mathrm{Na}^{+}\right)$. This assignment also agrees with the observed resonance position of the dominating ${ }^{1} \mathrm{H}$ MAS NMR signal at $3.2 \mathrm{ppm}$ in Fig. 5b, which corresponds to the previously published shift values for water at $\mathrm{Na}^{+}$ cations in zeolites (Kasai and Jones 1984). The water molecules contributing to the hydration shells around the $\mathrm{Na}^{+}$ cations are weakly physisorbed, since their signals have a line width of $500 \mathrm{~Hz}$ only hinting at a high mobility (Table 2, column 4).

The ${ }^{1} \mathrm{H}$ MAS NMR spectrum of the fully methanolloaded Na-ZSM-5 zeolite (Fig. 6b) is dominated by a signal with a much larger line width of $2500 \mathrm{~Hz}$ (Table 3, column 4) and the methanol has a slightly higher desorption enthalpy of $\Delta H=33 \mathrm{~kJ} / \mathrm{mol}$, when compared with the water-loaded Na-ZSM-5 (column 2). These findings indicate that the content of less mobile methanol molecules, directly coordinated at the $\mathrm{Na}^{+}$, is higher than the content of strongly adsorbed water molecules in the comparable case of fully hydrated $\mathrm{Na}-$ ZSM-5. After desorption of methanol and water at $373 \mathrm{~K}$, therefore, also a higher number of methanol $(1.1 \mathrm{mmol} / \mathrm{g})$ compared with the number of water $(0.4 \mathrm{mmol} / \mathrm{g})$ remains on Na-ZSM-5. Some of these methanol molecules must be involved in additional $\mathrm{H}$-bondings responsible for the broad low-field shifted ${ }^{1} \mathrm{H}$ MAS NMR signal at ca. $5 \mathrm{ppm}$. The high desorption enthalpies of $\Delta H=66$ and $74 \mathrm{~kJ} / \mathrm{mol}$ for the remaining water and methanol molecules (Tables 2 and 3, 
Table 3 Methanol desorption enthalpies $\Delta \mathrm{H}$, determined by TGADSC, amounts of adsorbed methanol, ${ }^{1} \mathrm{H}$ MAS NMR spectroscopic parameters (chemical shift $\delta_{1 \mathrm{H}}$, line width $\Delta v_{1 / 2}$, 'w' indicates weak signals), and adsorbate assignments for the MFI-type materials under study investigated after treatments at temperatures of 295 to $373 \mathrm{~K}$, 373 to $723 \mathrm{~K}$, and at $723 \mathrm{~K}$

\begin{tabular}{|c|c|c|c|c|}
\hline Porous support and adsorbed species & $\begin{array}{l}\Delta H \\
\text { in } \mathrm{kJ} / \mathrm{mol}\end{array}$ & $\begin{array}{l}\mathrm{CD}_{3} \mathrm{OH} \text { or } \\
\mathrm{OH} \text { in } \mathrm{mmol} / \\
\mathrm{g}^{\mathrm{d}}\end{array}$ & $\begin{array}{l}{ }^{1} \mathrm{H} \text { MAS NMR } \delta_{1 \mathrm{H}} \\
\text { in } \mathrm{ppm} / \Delta v_{1 / 2} \text { in } \mathrm{Hz}\end{array}$ & Assignments and references \\
\hline \multicolumn{5}{|l|}{ Silicalite-1 } \\
\hline Weakly adsorbed $\mathrm{CD}_{3} \mathrm{OH}^{\mathrm{a}}$ & 39 & 1.7 & $\begin{array}{l}3.7 / 450 \\
\text { ca. } 6 / 1400\end{array}$ & $\begin{array}{l}\text { Mobile } \mathrm{CD}_{3} \mathrm{OH} \text { cluster (Anderson et al. 1991; Salehirad } \\
\text { and Anderson 1998) } \\
\left(\mathrm{CD}_{3} \mathrm{OH}\right)_{\mathrm{n}} / \mathrm{SiOH} \text { (Anderson et al. 1991) }\end{array}$ \\
\hline Strongly bound $\mathrm{CD}_{3} \mathrm{OH}^{\mathrm{b}}$ & n.d. ${ }^{\mathrm{e}}$ & 0.1 & $\begin{array}{l}\text { ca. } 4 / 1500 \\
6.5 \mathrm{w} / 200\end{array}$ & $\begin{array}{l}\mathrm{CD}_{3} \mathrm{OH} / \mathrm{SiOH} \text { (Anderson et al. 1991) } \\
\mathrm{CD}_{3} \mathrm{OH} / \text { defect sites }\end{array}$ \\
\hline Pure $\mathrm{OH}^{\mathrm{c}}$ & - & 0.3 & $\begin{array}{l}1.8 / 200 \\
\text { ca. } 4 \mathrm{w} / 1500\end{array}$ & $\begin{array}{l}\text { SiOH (Hunger et al. 1996; Jiang et al. 2011) } \\
\text { H-bonded SiOH (Hunger et al. 1996; Jiang et al. 2011) }\end{array}$ \\
\hline \multicolumn{5}{|l|}{ Na-ZSM-5 } \\
\hline Weakly adsorbed $\mathrm{CD}_{3} \mathrm{OH}^{\mathrm{a}}$ & 33 & 1.0 & $2.9 / 2500$ & $\left(\mathrm{CD}_{3} \mathrm{OH}\right)_{\mathrm{n}} / \mathrm{Na}^{+}$(Anderson et al. 1991) \\
\hline Strongly bound $\mathrm{CD}_{3} \mathrm{OH}^{\mathrm{b}}$ & 74 & 1.1 & $\begin{array}{l}2.5 / 1800 \\
\text { ca. } 5 \mathrm{w} / 3000\end{array}$ & $\begin{array}{l}\mathrm{CD}_{3} \mathrm{OH} / \mathrm{Na}^{+} \text {(Anderson et al. 1991) } \\
\left(\mathrm{CD}_{3} \mathrm{OH}\right)_{\mathrm{n}} / \mathrm{SiOH} \text { (Anderson et al. 1991) }\end{array}$ \\
\hline Pure $\mathrm{OH}^{\mathrm{c}}$ & - & 0.1 & $\begin{array}{l}1.8 / 200 \\
\text { ca. } 3 \mathrm{w} / 400\end{array}$ & $\begin{array}{l}\text { SiOH (Hunger et al. 1996; Jiang et al. 2011) } \\
\text { H-bonded SiOH (Hunger et al. 1996; Jiang et al. 2011) }\end{array}$ \\
\hline \multicolumn{5}{|l|}{ H-ZSM-5 } \\
\hline Weakly adsorbed $\mathrm{CD}_{3} \mathrm{OH}^{\mathrm{a}}$ & 34 & 1.4 & $7.4 / 1300$ & $\begin{array}{l}\left(\mathrm{CD}_{3} \mathrm{OH}\right)_{\mathrm{n}} / \mathrm{Si}(\mathrm{OH}) \mathrm{Al} \text { (Anderson et al. 1991; Hunger and } \\
\text { Horvath 1996) }\end{array}$ \\
\hline Strongly bound $\mathrm{CD}_{3} \mathrm{OH}^{\mathrm{b}}$ & $36^{\mathrm{f}}$ & 0.8 & $\begin{array}{l}2.8 / 800 \\
6.5 \mathrm{w} / 200 \\
9.2 / 2000\end{array}$ & $\begin{array}{l}\mathrm{CD}_{3} \mathrm{OH} / \mathrm{SiOH} \text { (Anderson et al. 1991) } \\
\mathrm{CD}_{3} \mathrm{OH} / \mathrm{defect} \text { sites (Hunger et al. 1991) } \\
\mathrm{CD}_{3} \mathrm{OH} / \mathrm{Si}(\mathrm{OH}) \mathrm{Al} \text { (Anderson et al. 1991; Hunger and } \\
\text { Horvath 1996) }\end{array}$ \\
\hline Pure $\mathrm{OH}^{\mathrm{c}}$ & - & 0.6 & $\begin{array}{l}1.8 / 200 \\
\text { ca. } 3 \mathrm{w} / 400 \\
4.0 / 400 \\
5.3 / 1400\end{array}$ & $\begin{array}{l}\text { SiOH (Hunger et al. 1996; Jiang et al. 2011) } \\
\text { H-bonded SiOH (Hunger et al. 1996; Jiang et al. 2011) } \\
\mathrm{Si}(\mathrm{OH}) \mathrm{Al} \text { (Hunger et al. 1996; Jiang et al. 2011) } \\
\text { Disturbed } \mathrm{Si}(\mathrm{OH}) \mathrm{Al} \text { (Hunger et al. 1996; Jiang et al. 2011) }\end{array}$ \\
\hline
\end{tabular}

${ }^{a}$ Methanol desorbed between 295 and $373 \mathrm{~K}$

${ }^{\mathrm{b}}$ Methanol desorbed between 373 and $723 \mathrm{~K}$

${ }^{\mathrm{c}}$ Hydroxyl groups determined after evacuation at $723 \mathrm{~K}$

${ }^{\mathrm{d}}$ Determined by ${ }^{1} \mathrm{H}$ MAS NMR spectroscopy using an external intensity standard

${ }^{\mathrm{e}}$ Not determined

${ }^{\mathrm{f}}$ Methanol desorbed between 373 and $473 \mathrm{~K}$; above $493 \mathrm{~K}$ the MTO reaction is initiated

column 2), however, indicate that most of these molecules are coordinated at $\mathrm{Na}^{+}$cations (see Sect. 1).

\subsubsection{H-ZSM-5}

For the fully water- and methanol-loaded H-ZSM-5 in the adsorption equilibrium at room temperature, the ratio of the total numbers of adsorbed water and methanol (3.2 and $2.2 \mathrm{mmol} / \mathrm{g}$, respectively) is similar to that found for Na-ZSM-5 (3.5 and $2.1 \mathrm{mmol} / \mathrm{g}$, respectively) under same conditions (Tables 2 and 3, column 3). The desorption enthalpies determined for both samples are very close $(\Delta H=27$ to $34 \mathrm{~kJ} / \mathrm{mol})$. On the other hand, the nature of the adsorbate complexes must be different, since the $\mathrm{Na}^{+}$cations in Na-ZSM-5 are replaced by Brønsted acidic $\mathrm{Si}(\mathrm{OH}) \mathrm{Al}$ groups in $\mathrm{H}-\mathrm{ZSM}-5$ (0.49 mmol/g, see Sect. 3.2.3.). In H-ZSM-5, both water and methanol do not form mobile clusters, as in Silicalite-1, which is evidenced by the large line width (1100 to $1300 \mathrm{~Hz})$ of the dominating ${ }^{1} \mathrm{H}$ MAS NMR signals in Figs. 5c and $6 \mathrm{c}$ and the desorption enthalpies of $\Delta H=31$ and $34 \mathrm{~kJ} /$ mol (Tables 2 and 3, column 2), which are lower compared with the evaporation heats of water $(41 \mathrm{~kJ} / \mathrm{mol})$ and methanol $(37 \mathrm{~kJ} / \mathrm{mol})$. The high chemical shift values of these broad signals of $5.9 \mathrm{ppm}$ for water and $7.4 \mathrm{ppm}$ for methanol in H-ZSM-5 indicate that water and methanol interact with $\mathrm{Si}(\mathrm{OH}) \mathrm{Al}$ ) groups, which is accompanied by a partial protonation, i.e. chemisorption, of the adsorbed molecules (see Sect. 1). For the waterloaded H-ZSM-5, therefore, the rapid exchange between H-bonded water (3 ppm, Table 2, column 4) and hydroxonium ions [12 ppm (Haase and Sauer 1994)] leads to 

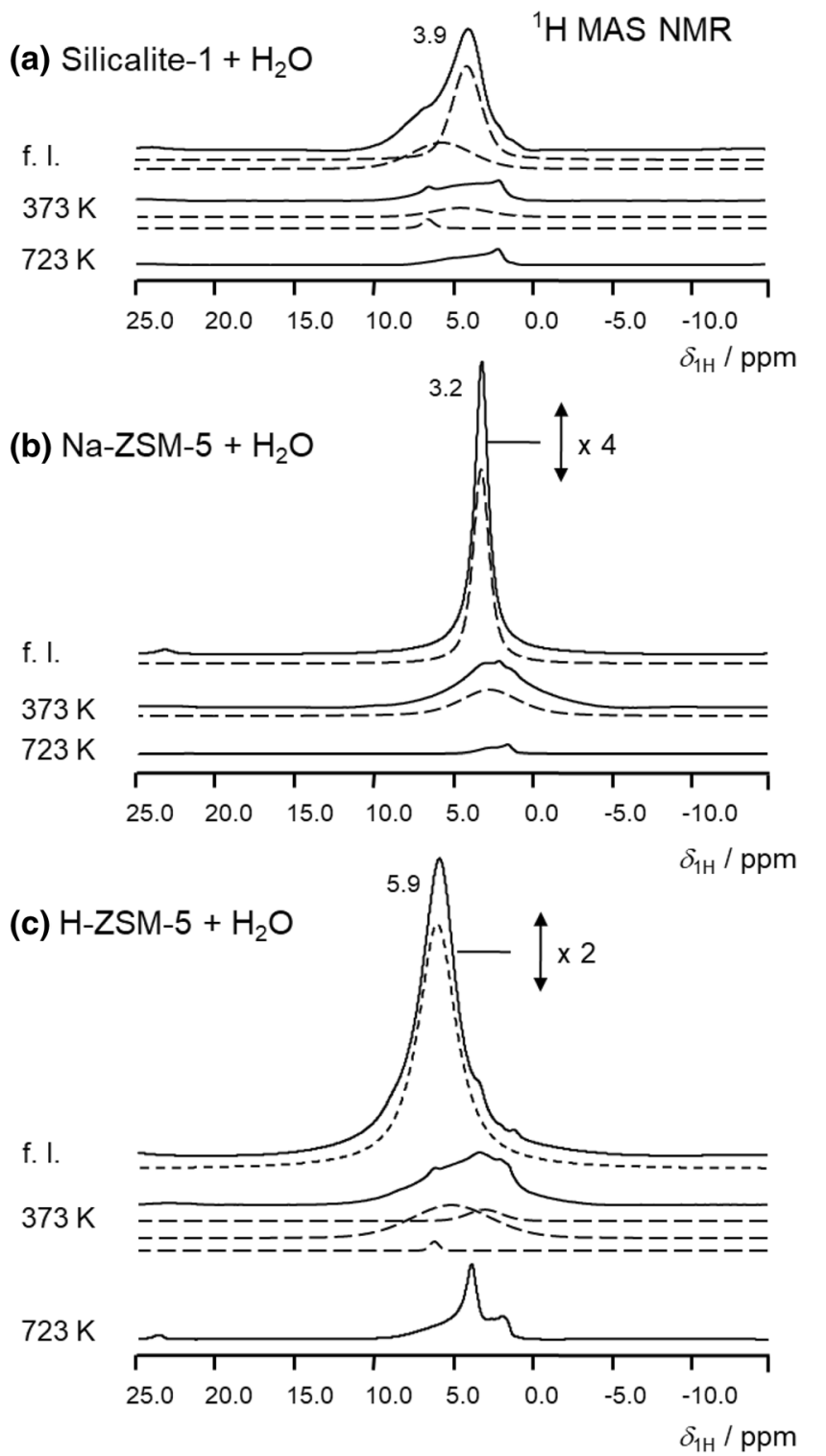

Fig. $5{ }^{1} \mathrm{H}$ MAS NMR spectra of Silicalite-1 (a), Na-ZSM-5 (b), and H-ZSM-5 (c) recorded in the fully loaded state (f.l., top) and after desorption of water at $373 \mathrm{~K}$ (middle) and $723 \mathrm{~K}$ (bottom). The dashed curves indicate the shapes of the water signals used for simulating the experimental spectra. Table 2 , column 4 , gives an overview on all signals and their assignment in column 5

a signal at $6 \mathrm{ppm}$. For the methanol-loaded H-ZSM-5, on the other hand, a rapid exchange between H-bonded methanol (4 ppm, Table 3, column 4) and methoxonium ions [17 ppm (Haase and Sauer 1995)] occurs, which results in a signal at $7.4 \mathrm{ppm}$, i.e. in a higher low-field shift compared with water in H-ZSM-5. After desorption at $373 \mathrm{~K}$, the contents of the physisorbed adsorbate molecules are significantly decreased and the above-mentioned chemisorbed adsorbate molecules have an increasing influence on the signal position. Therefore, a further
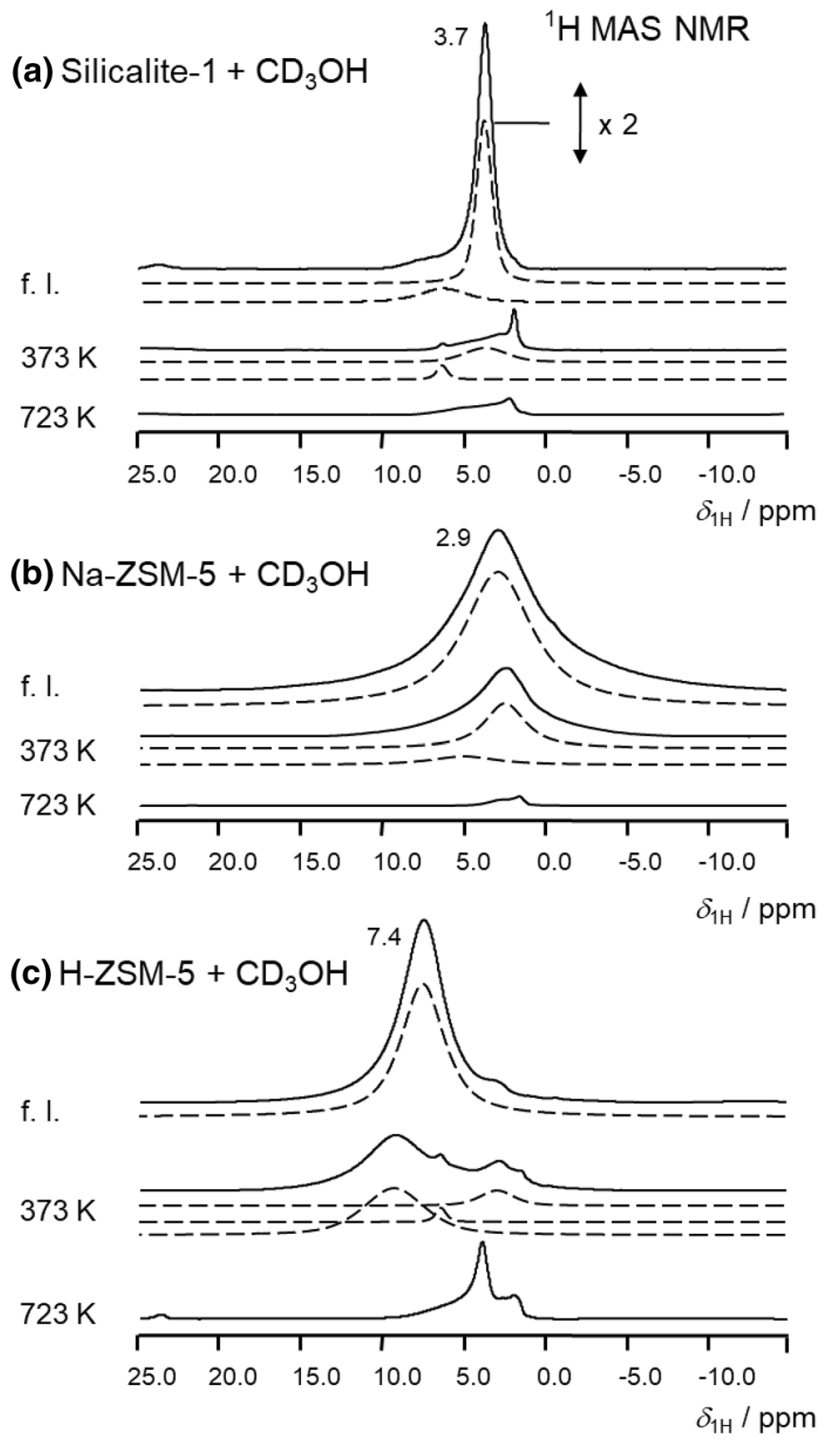

Fig. $6{ }^{1} \mathrm{H}$ MAS NMR spectra of Silicalite-1 (a), Na-ZSM-5 (b), and H-ZSM-5 (c) recorded in the fully loaded state (f.l., top) and after desorption of methanol at $373 \mathrm{~K}$ (middle) and $723 \mathrm{~K}$ (bottom). The dashed curves indicate the shapes of the methanol $\mathrm{OH}$ signals used for simulating the experimental spectra. Table 3, column 4, gives an overview on all signals and their assignment in column 5

low-field shift of the adsorbate signals to $6.5 \mathrm{ppm}$ for remaining water and to $9.2 \mathrm{ppm}$ for remaining methanol on H-ZSM-5 occurred (Tables 2 and 3, column 4). The number of remaining water and methanol molecules is 0.3 and $0.8 \mathrm{mmol} / \mathrm{g}$ (Table 2 and 3 , column 3 ), while their desorption enthalpies of $\Delta H=63$ and $36 \mathrm{~kJ} / \mathrm{mol}$ indicate, in contrast to previous desorption enthalpies, the water should stronger bound than methanol on H-ZSM-5 (column 2). However, in this connection it must be noted that methanol starts to dehydrate at $493 \mathrm{~K}$, which strongly decreases the significance of the $\Delta H$ value for this adsorbate molecule. As observed for the water- and 
methanol-loaded Silicalite-1 after desorption at $373 \mathrm{~K}$, weak signals at $6.5 \mathrm{ppm}$ occur in the ${ }^{1} \mathrm{H}$ MAS NMR spectra of H-ZSM-5, which indicate a coordination of very few adsorbate molecules at defect sites.

Summarizing, by ${ }^{1} \mathrm{H}$ MAS NMR spectroscopy it was shown that significantly less water and methanol can be adsorbed at Silicalite- 1 in form of mobile clusters in comparison with Na-ZSM-5 and H-ZSM-5. Silicalite-1 prefers adsorption of methanol over water, i.e. it is more hydrophobic than organophilic, which is in contrast to the more hydrophilic zeolites Na-ZSM-5 and H-ZSM-5. On completely water- and methanol-loaded Na-ZSM-5, these molecules are mainly adsorbed at the $\mathrm{Na}^{+}$cations, while partially protonated adsorbate clusters exist at the Brønsted acid sites in H-ZSM-5. After desorption at $373 \mathrm{~K}$, Na-ZSM-5 and H-ZSM-5 contain more methanol than water. Remaining water and methanol are strongly bound at $\mathrm{Na}^{+}$cations and acidic hydroxyl protons, whereas no remaining adsorbates could be found on Silicalite-1.

\subsection{Comparative study of water and methanol adsorption on SBA-15}

\subsubsection{Siliceous SBA-15}

Due to the larger mesopores of SBA-15, this material is characterized by significantly higher total amounts of water $(6.8 \mathrm{mmol} / \mathrm{g})$ and methanol $(6.1 \mathrm{mmol} / \mathrm{g})$ present in the pores in the adsorption equilibrium at room temperature (Tables 4 and 5, column 3), compared with Silicalite- 1 (in total 0.5 and $1.8 \mathrm{mmol} / \mathrm{g}$, respectively). The desorption enthalpies of $\Delta H=41$ and $42 \mathrm{~kJ} / \mathrm{mol}$ for the weakly adsorbed water and methanol on SBA-15 (Tables 4 and 5, column 2), respectively, indicate that these water and methanol molecules mainly exist as bulk clusters. The above-mentioned desorption enthalpies agree with the evaporation heat of water of $41 \mathrm{~kJ} / \mathrm{mol}$ (Flanigen et al. 1978) and methanol of $37 \mathrm{~kJ} / \mathrm{mol}$ (Schmeling and Strey 1983). This assignment is also supported by the chemical shifts of the dominating ${ }^{1} \mathrm{H}$ MAS NMR signals of water $(4.2 \mathrm{ppm})$ and methanol $(4.8 \mathrm{ppm})$ and their small line widths (Figs. 7a and 8a, respectively). After

adsorbate assignments for the SBA-15 materials under study investigated after treatments at temperatures of 295 to $373 \mathrm{~K}, 373$ to $723 \mathrm{~K}$, and at $723 \mathrm{~K}$
Table 4 Water desorption enthalpies $\Delta H$, determined by TGA-DSC, amounts of adsorbed water, ${ }^{1} \mathrm{H}$ MAS NMR spectroscopic parameters (chemical shift $\delta_{1 \mathrm{H}}$, line width $\Delta v_{1 / 2}$, 'w' indicates weak signals), and

\begin{tabular}{|c|c|c|c|c|}
\hline Porous support and adsorbed species & $\Delta H$ in $\mathrm{kJ} / \mathrm{mol}$ & $\begin{array}{l}\mathrm{H}_{2} \mathrm{O} \text { or } \mathrm{OH} \\
\text { in } \mathrm{mmol} / \mathrm{g}^{\mathrm{d}}\end{array}$ & $\begin{array}{l}{ }^{1} \mathrm{H} \text { MAS NMR } \delta_{1 \mathrm{H}} \\
\text { in } \mathrm{ppm} / \Delta v_{1 / 2} \text { in } \mathrm{Hz}\end{array}$ & Assignments and references \\
\hline \multicolumn{5}{|l|}{ SBA-15 } \\
\hline Weakly adsorbed $\mathrm{H}_{2} \mathrm{O}^{\mathrm{a}}$ & 41 & 5.9 & $\begin{array}{l}4.2 / 400 \\
5.2 \mathrm{w} / 1000\end{array}$ & $\begin{array}{l}\text { Mobile } \mathrm{H}_{2} \mathrm{O} \text { cluster (Batamack et al. 1991) } \\
\left(\mathrm{H}_{2} \mathrm{O}\right)_{\mathrm{n}} / \mathrm{SiOH} \text { (Grünberg et al. 2004) }\end{array}$ \\
\hline Strongly bound $\mathrm{H}_{2} \mathrm{O}^{\mathrm{b}}$ & n.d. ${ }^{\mathrm{e}}$ & 0.9 & ca. $3 / 1200$ & $\mathrm{H}_{2} \mathrm{O} / \mathrm{SiOH}$ (Grünberg et al. 2004) \\
\hline Pure $\mathrm{OH}^{\mathrm{c}}$ & - & 1.9 & $\begin{array}{l}1.8 / 200 \\
\text { ca. } 2.5 \mathrm{w} / 1000\end{array}$ & $\begin{array}{l}\text { SiOH (Hunger et al. 1996; Jiang et al. 2011) } \\
\text { H-bonded SiOH (Hunger et al. 1996; Jiang et al. 2011) }\end{array}$ \\
\hline \multicolumn{5}{|l|}{$\mathrm{Na}-[\mathrm{Al}] \mathrm{SBA}-15$} \\
\hline Weakly adsorbed $\mathrm{H}_{2} \mathrm{O}^{\mathrm{a}}$ & 38 & 6.6 & $\begin{array}{l}4.4 / 350 \\
5.6 \mathrm{w} / 1400\end{array}$ & $\begin{array}{l}\text { Mobile } \mathrm{H}_{2} \mathrm{O} \text { cluster (Batamack et al. 1991) } \\
\left(\mathrm{H}_{2} \mathrm{O}\right)_{\mathrm{n}} / \mathrm{SiOH} \text { (Grünberg et al. 2004) }\end{array}$ \\
\hline Strongly bound $\mathrm{H}_{2} \mathrm{O}^{\mathrm{b}}$ & 44 & 0.7 & ca. $3 / 1500$ & $\mathrm{H}_{2} \mathrm{O} / \mathrm{SiOH}$ (Kasai and Jones 1984) \\
\hline Pure $\mathrm{OH}^{\mathrm{c}}$ & - & 1.1 & $\begin{array}{l}1.8 / 200 \\
\text { ca. } 2.5 \mathrm{w} / 400\end{array}$ & $\begin{array}{l}\text { SiOH (Hunger et al. 1996; Jiang et al. 2011) } \\
\text { H-bonded SiOH (Hunger et al. 1996; Jiang et al. 2011) }\end{array}$ \\
\hline \multicolumn{5}{|l|}{ H-[Al]SBA-15 } \\
\hline Weakly adsorbed $\mathrm{H}_{2} \mathrm{O}^{\mathrm{a}}$ & 35 & 4.4 & $\begin{array}{l}4.8 / 600 \\
6.8 \mathrm{w} / 1200\end{array}$ & $\begin{array}{l}\text { Mobile } \mathrm{H}_{2} \mathrm{O} \text { cluster (Batamack et al. 1991) } \\
\left(\mathrm{H}_{2} \mathrm{O}\right)_{\mathrm{n}} / \mathrm{SiOH} \text { (Grünberg et al. 2004) }\end{array}$ \\
\hline Strongly bound $\mathrm{H}_{2} \mathrm{O}^{\mathrm{b}}$ & 46 & 0.7 & $3.5 / 1200$ & $\begin{array}{l}\left(\mathrm{H}_{2} \mathrm{O}\right)_{\mathrm{n}} / \mathrm{SiOH} \text { (Grünberg et al. 2004) and } \mathrm{H}_{2} \mathrm{O} / \\
\mathrm{SiOH} \cdots \mathrm{Al}\end{array}$ \\
\hline Pure $\mathrm{OH}^{\mathrm{c}}$ & - & 0.9 & $\begin{array}{l}1.8 / 200 \\
\text { ca. } 2.5 \mathrm{w} / 500 \\
\text { ca. } 4 \mathrm{w} / 500\end{array}$ & $\begin{array}{l}\text { SiOH (Hunger et al. 1996; Jiang et al. 2011) } \\
\text { H-bonded SiOH (Hunger et al. 1996; Jiang et al. 2011) } \\
\text { SiOH } \cdots \text { Al (Hunger et al. 1996; Jiang et al. 2011) }\end{array}$ \\
\hline
\end{tabular}

${ }^{\mathrm{a}}$ Water desorbed between 295 and $373 \mathrm{~K}$

${ }^{\mathrm{b}}$ Water desorbed between 373 and $723 \mathrm{~K}$

${ }^{c}$ Hydroxyl groups determined after evacuation at $723 \mathrm{~K}$

${ }^{\mathrm{d}}$ Determined by ${ }^{1} \mathrm{H}$ MAS NMR spectroscopy using an external intensity standard

${ }^{\mathrm{e}}$ Not determined 


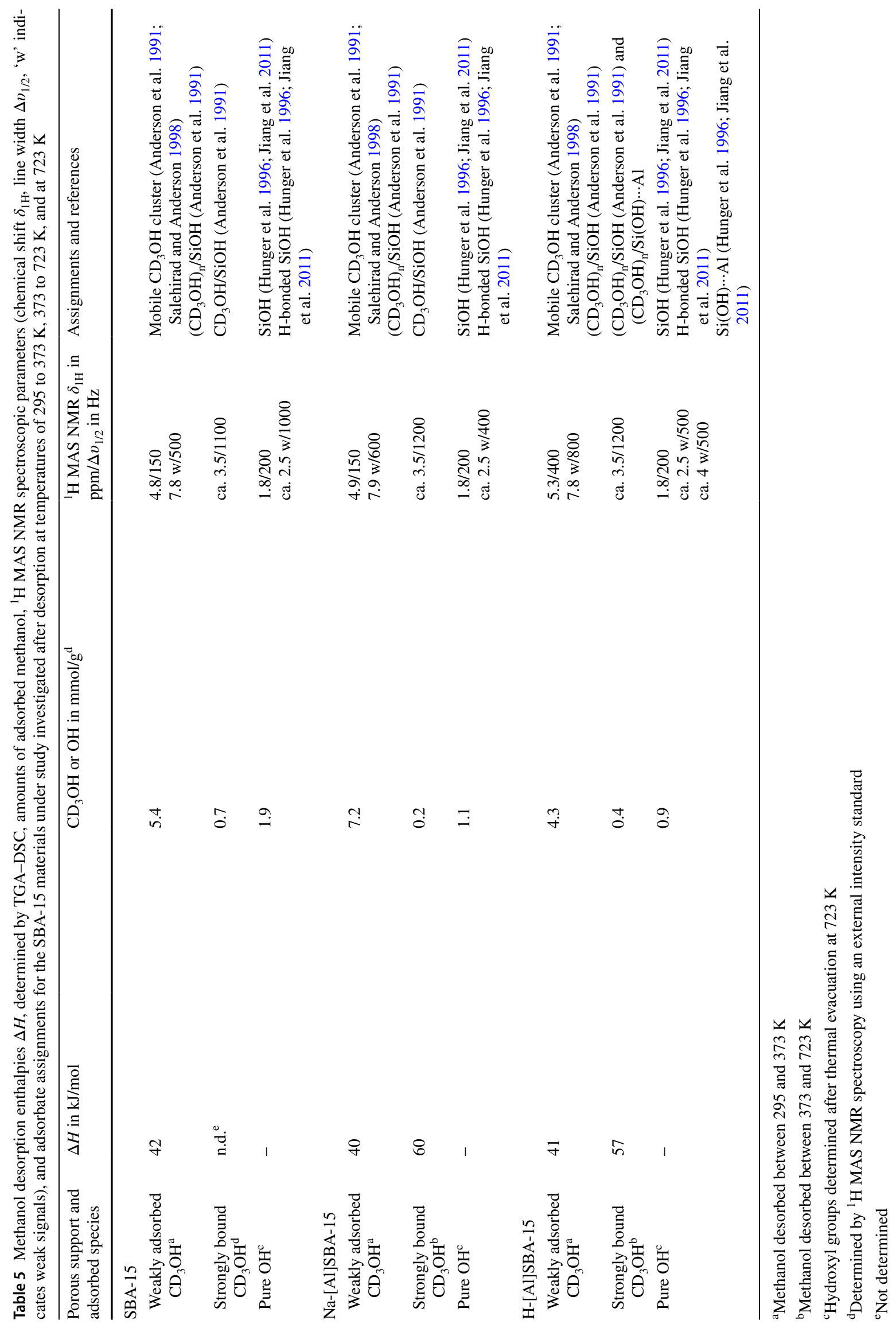



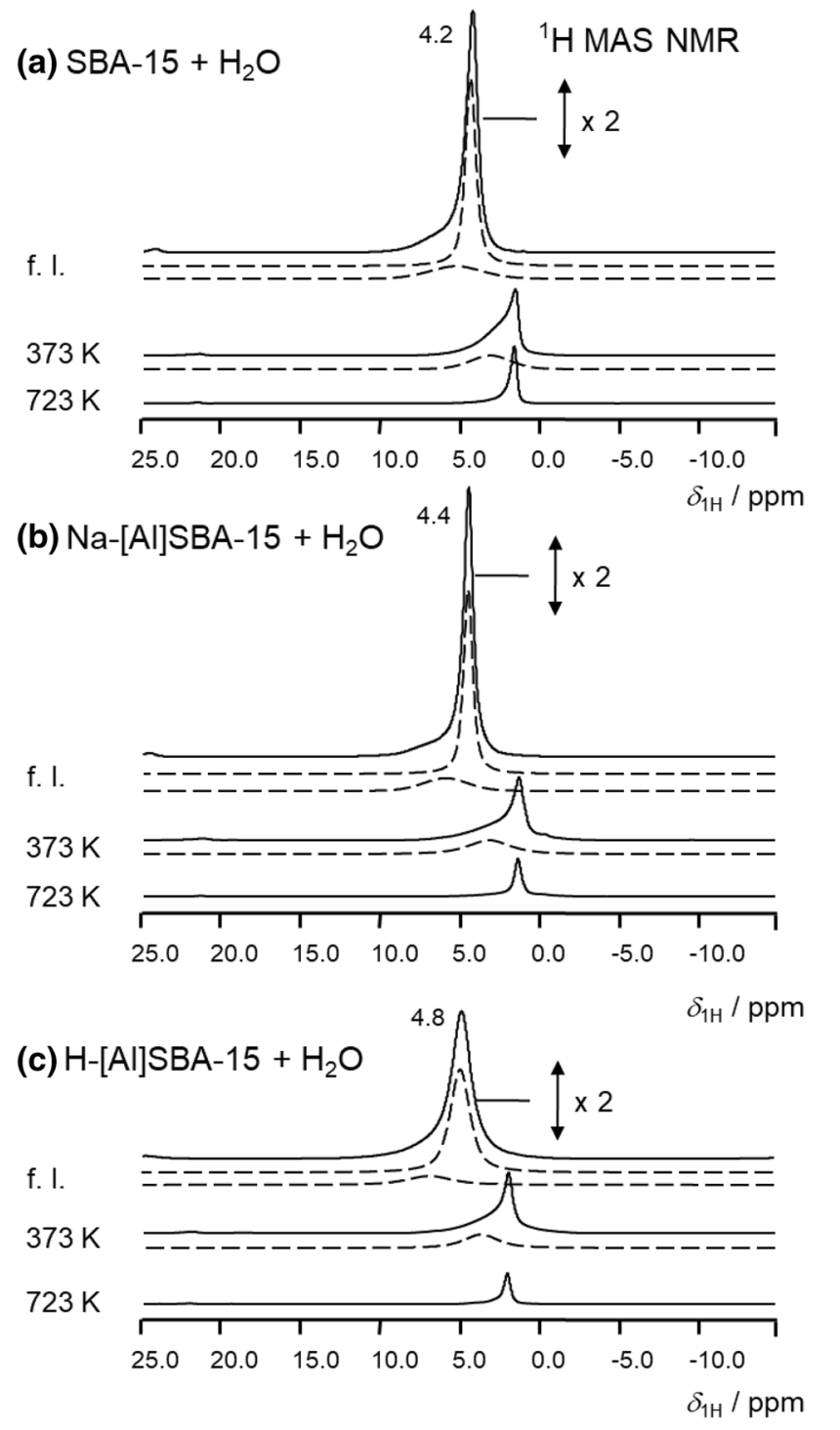

Fig. $7{ }^{1}$ H MAS NMR spectra of siliceous SBA-15 (a), Na-[Al]SBA15 (b), and H-[Al]SBA-15 (c) recorded in the fully loaded state (f.l., top) and after desorption of water at $373 \mathrm{~K}$ (middle) and $723 \mathrm{~K}$ (bottom). The dashed curves indicate the shapes of the water signals used for simulating the experimental spectra. Table 4, column 4, gives an overview on all signals and their assignment in column 5

the desorption at $373 \mathrm{~K}$, more water $(0.9 \mathrm{mmol} / \mathrm{g})$ than methanol $(0.7 \mathrm{mmol} / \mathrm{g})$ remains on the siliceous SBA15 , which could be due to the presence of $\mathrm{Q}^{2}$-type $\mathrm{SiOH}$ groups in this material and their specific interaction with water molecules (see Sect. 3.2.1). Considering the abovementioned amounts of adsorbate molecules remaining after desorption at $373 \mathrm{~K}$, the siliceous SBA-15 is slightly more hydrophilic than organophilic. The large line widths of the ${ }^{1} \mathrm{H}$ MAS NMR signals of 1100 to $1200 \mathrm{~Hz}$ caused by the remaining adsorbates indicate a low mobility of these molecules (Tables 4 and 5, column 4). The chemical shifts observed for the remaining water ( $3 \mathrm{ppm})$ and methanol

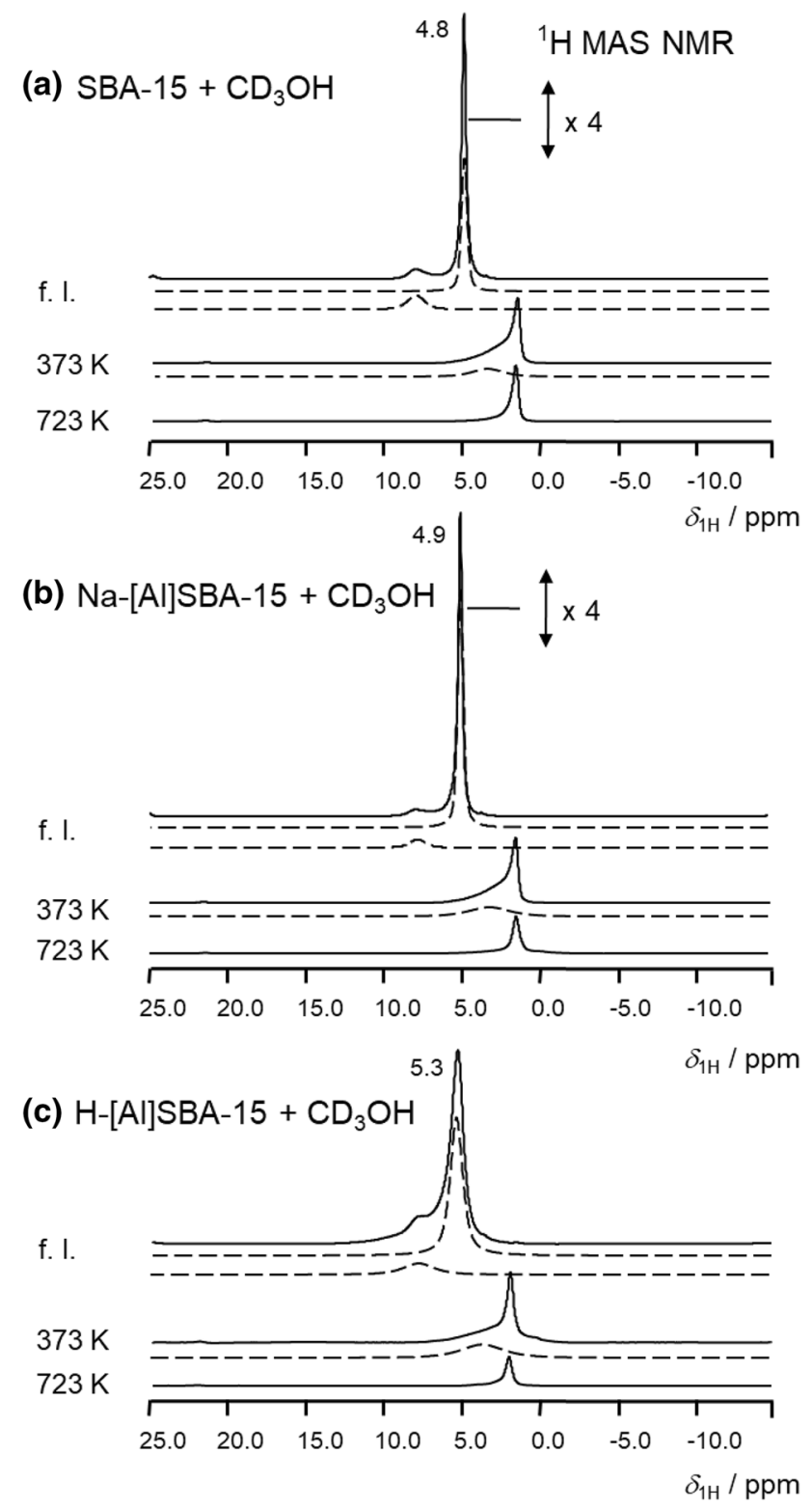

Fig. $8{ }^{1}$ H MAS NMR spectra of siliceous SBA-15 (a), Na-[Al]SBA15 (b), and H-[Al]SBA-15 (c) recorded in the fully loaded state (f.l., top) and after desorption of methanol at $373 \mathrm{~K}$ (middle) and $723 \mathrm{~K}$ (bottom). The dashed curves indicate the shapes of the methanol $\mathrm{OH}$ signals used for simulating the experimental spectra. Table 5, column 4 , gives an overview on all signals and their assignment in column 5

(3.5 ppm) molecules support an assignment to $\mathrm{H}$-bonded molecules (Table 4 and 5, column 4).

\subsubsection{Na-[AI]SBA-15}

The modification of the siliceous SBA-15 with sodium aluminate is accompanied by an increase of the total water $(7.3 \mathrm{mmol} / \mathrm{g})$ and methanol $(7.4 \mathrm{mmol} / \mathrm{g})$ loading in the adsorption equilibrium at room temperature for $\mathrm{Na}-[\mathrm{Al}]$ 
SBA-15 compared with the siliceous material (Tables 4 and 5 , column 3 ). Because of the weak adsorption of these molecules on the sodium cations (see Sect. 3.2.2.), the above-mentioned enhanced adsorption properties hint at an inductive effect of aluminum species incorporated into the walls of SBA-15 on the adsorption properties of $\mathrm{Q}^{2}$ - and $\mathrm{Q}^{3}$-type $\mathrm{SiOH}$ groups, being the main adsorption sites in this material (see Sect. 3.2.2.). Like for the siliceous SBA15 , the desorption enthalpies for the weakly adsorbed water $(\Delta H=38 \mathrm{~kJ} / \mathrm{mol})$ and methanol $(\Delta H=40 \mathrm{~kJ} / \mathrm{mol})$ molecules are very similar to the evaporation heats of these adsorbates (Table 4 and 5, column 2), which indicates that these adsorbates exist as mobile bulk clusters. This latter assignment is supported by chemical shifts of the dominating ${ }^{1} \mathrm{H}$ MAS NMR signals of water (4.4 ppm) and methanol $(4.9$ ppm) in Figs. $7 \mathrm{~b}$ and $8 \mathrm{~b}$ and their small line widths of 350 and $150 \mathrm{~Hz}$, respectively (Tables 4 and 5, column 4). After desorption at $373 \mathrm{~K}$, the remaining water and methanol molecules are mainly adsorbed at $\mathrm{SiOH}$ groups as indicated by the chemical shifts and line widths of their ${ }^{1} \mathrm{H}$ MAS NMR signals (Table 4 and 5, column 4). The lower desorption enthalpies of the remaining water and methanol molecules of $\Delta H=44 \mathrm{~kJ} / \mathrm{mol}$ and $60 \mathrm{~kJ} / \mathrm{mol}$ (Tables 4 and 5, column 2), respectively, determined after desorption at $373 \mathrm{~K}$ in comparison with these values determined for Na-ZSM-5 ( $\Delta H=66 \mathrm{~kJ} / \mathrm{mol}$ and $74 \mathrm{~kJ} / \mathrm{mol}$, respectively) indicate that the remaining adsorbate molecules in Na-[Al] SBA-15 are not or only sparsely coordinated at $\mathrm{Na}^{+}$cations. This finding indicates that the water and methanol adsorption occurs at $\mathrm{SiOH}$ groups, which are weakly influenced by distantly incorporated framework aluminum species into the pore walls of SBA-15. According to the numbers of $0.7 \mathrm{mmol} / \mathrm{g}$ water and $0.2 \mathrm{mmol} / \mathrm{g}$ methanol remaining after the desorption at $373 \mathrm{~K}, \mathrm{Na}$-[Al]SBA-15 is significantly less organophilic than the siliceous SBA-15 (0.9 and $0.7 \mathrm{mmol} / \mathrm{g}$, respectively) under the same conditions and for a low adsorbate loading (Tables 4 and 5, column 3).

\subsubsection{H-[Al]SBA-15}

The desorption enthalpies of water and methanol on $\mathrm{H}-[\mathrm{Al}]$ SBA-15 for the adsorption equilibrium at room temperature are in the ranges of $\Delta H=35-38 \mathrm{~kJ} / \mathrm{mol}$ and $\Delta H=40-41 \mathrm{~kJ} /$ mol, respectively, for these materials (Tables 4 and 5, column 2), which is very similar to these values obtained for Na-[Al]SBA-15. Differences between H-[Al]SBA-15 and Na-[Al]SBA-15 are lower total loadings of water and methanol of $5.1 \mathrm{mmol} / \mathrm{g}$ and $4.7 \mathrm{mmol} / \mathrm{g}$. Higher chemical shift values of the ${ }^{1} \mathrm{H}$ MAS NMR signals of the water and methanol molecules of 4.8 and $5.3 \mathrm{ppm}$ appear for H-[Al]SBA-15 (Figs. 7c and 8c). This effect can be explained by the presence of $\mathrm{Br} \varnothing n s t e d$ acidic $\mathrm{OH}$ groups $(\mathrm{Si}(\mathrm{OH}) \cdots \mathrm{Al})$ in $\mathrm{H}-[\mathrm{Al}]$ SBA-15, which is accompanied by a partial protonation of the adsorbate molecules directly adsorbed at these surface sites (see Sects. 1 and 3.2.3). The desorption enthalpies of the remaining water and methanol molecules of $\Delta H=46$ and $57 \mathrm{~kJ} / \mathrm{mol}$ (Table 4 and Table 5, column 2), determined after desorption at $373 \mathrm{~K}$, are very similar to the values obtained for Na-[Al]SBA-15 (44 and $60 \mathrm{~kJ} / \mathrm{mol}$, respectively). This supports an only negligible effect of the Brønsted acidic $\mathrm{OH}$ groups $(\mathrm{Si}(\mathrm{OH}) \cdots \mathrm{Al})$ in $\mathrm{H}-[\mathrm{Al}] \mathrm{SBA}-15$ on the adsorption properties of this material. Due to the low concentration of these acid sites of $0.18 \mathrm{mmol} / \mathrm{g}$ (see Sect. 3.2.3.), most of the $0.7 \mathrm{mmol} / \mathrm{g}$ water and $0.4 \mathrm{mmol} / \mathrm{g}$ methanol molecules remaining after the desorption at $373 \mathrm{~K}$ (Tables 4 and 5, column 3) should be adsorbed at $\mathrm{SiOH}$ groups, which are weakly influenced by distantly incorporated framework aluminum species, as also discussed for Na-[Al]SBA-15. On the other hand, the above-mentioned numbers (of remaining water and methanol molecules) indicate that $\mathrm{H}$-[Al]SBA-15 is more hydrophilic than organophilic. But this adsorbate ratio is not so pronounced as found for Na-[Al]SBA-15 with $0.7 \mathrm{mmol} / \mathrm{g}$ water and $0.2 \mathrm{mmol} / \mathrm{g}$ methanol molecules for a low adsorbate loading.

Summarizing, the adsorption capacity of SBA-15 materials is stronger influenced by the large mesopore volume than by surface sites inside the pores, such as $\mathrm{SiOH}$ groups, $\mathrm{Na}^{+}$cations, and Brønsted acid sites. This is the reason for similar desorption enthalpies of the completely waterand methanol loaded samples. After desorption at $373 \mathrm{~K}$, strongly bound water and, in a smaller quantity, methanol molecules remain, presumably at the $\mathrm{Q}^{2}$-type $\mathrm{SiOH}$ groups of the siliceous SBA-15 material, that are absent in Silicalite-1. On Na-[Al]SBA-15 and H-[Al]SBA-15, in contrast to Na-ZSM-5 and H-ZSM-5, water and methanol adsorb mainly at $\mathrm{SiOH}$ groups weakly influenced by distant framework aluminum species. They adsorb to a smaller extend at $\mathrm{Na}^{+}$cations and at the Brønsted acidic sites.

\section{Conclusions}

By combination of TGA/DSC with solid-state NMR investigations on both siliceous and aluminum-containing MFItype zeolites and mesoporous SBA-15 materials with comparable functionalities, an improved insight into the various adsorption states of water and methanol on these materials was gained.

For siliceous Silicalite-1 as well as siliceous SBA15 , the experimentally determined desorption enthalpies $(38-42 \mathrm{~kJ} / \mathrm{mol})$ and the dominating ${ }^{1} \mathrm{H}$ MAS NMR signals in the spectra of the samples saturated with water and methanol indicate, that a high content of these adsorbate molecules exist as mobile bulk clusters. By ${ }^{29} \mathrm{Si} \mathrm{CPMAS}$ NMR, the organophilicity of Silicalite-1 could be supported by stronger methanol than water interactions with 
surface $\mathrm{SiOH}$ groups of $\mathrm{Q}^{3}$-type. By the same spectroscopic method, $\mathrm{SiOH}$ groups of $\mathrm{Q}^{2}$-type could be identified on SBA-15, which are probably responsible for the strong water interactions. Therefore, the surface of siliceous SBA-15 is more hydrophilic than organophilic, in contrast to Silicalite-1.

For the aluminum- and sodium-containing materials and low adsorbate loadings, a more differentiated picture occurred. In Na-ZSM-5, the $\mathrm{Na}^{+}$cations are the most important adsorption sites for water and methanol. Also in low loadings after desorption at $373 \mathrm{~K}$, the remaining water and methanol are coordinated at these cations, as evidenced by ${ }^{23} \mathrm{Na}$ MAS NMR spectroscopy. This finding agrees well with the high desorption enthalpies of $\Delta H=66$ to $74 \mathrm{~kJ} /$ mol for the two adsorbate molecules. For the Na-[Al]SBA15 , in contrast, only a very weak interaction of water and methanol with sodium species could be observed. Similarly, the aluminum species introduced into Na-[Al]SBA-15 were only slightly affected by remaining water and methanol after desorption at $373 \mathrm{~K}$, as indicates by ${ }^{27} \mathrm{Al}$ MAS NMR spectroscopy. The slightly increased desorption enthalpies $(\Delta H=46-60 \mathrm{~kJ} / \mathrm{mol})$ determined for water and methanol on this material compared with siliceous SBA-15 are tentatively explained by $\mathrm{SiOH}$ groups, which are weakly influenced by distantly incorporated framework aluminum species. Interestingly, the amount of remaining water $(0.7 \mathrm{mmol} / \mathrm{g})$ and methanol $(0.2 \mathrm{mmol} / \mathrm{g})$ after the desorption at $373 \mathrm{~K}$ indicates, that Na-[Al]SBA-15 is less organophilic than the siliceous SBA-15 (0.9 and $0.7 \mathrm{mmol} / \mathrm{g}$, respectively) under similar conditions. Thus, significantly more water $(0.7 \mathrm{mmol} / \mathrm{g})$ than methanol $(0.2 \mathrm{mmol} / \mathrm{g})$ remains adsorbed on $\mathrm{Na}-[\mathrm{Al}]$ SBA-15 after desorption at $373 \mathrm{~K}$.

The adsorption properties of H-ZSM-5 are strongly influenced by the presence of Brønsted acidic bridging $\mathrm{OH}$ groups $(0.49 \mathrm{mmol} / \mathrm{g})$ and the partial protonation of adsorbed water and methanol molecules. This partial adsorbate protonation is indicated by low-field shifts of the ${ }^{1} \mathrm{H}$ MAS NMR signals and higher desorption enthalpies compared with Silicalite-1. After desorption of water and methanol at $373 \mathrm{~K}$, more methanol than water remains adsorbed $(0.8 \mathrm{mmol} / \mathrm{g}$ and $0.3 \mathrm{mmol} / \mathrm{g})$. For H-[Al]SBA15 , the presence of $0.18 \mathrm{mmol} / \mathrm{g}$ Brønsted acidic surface $\mathrm{OH}$ groups could be determined via ammonia adsorption and ${ }^{1} \mathrm{H}$ MAS NMR spectroscopy. On the other hand, this small number of acid sites can have only a small influence on the adsorption of water and methanol, because of the high amount of $0.7 \mathrm{mmol} / \mathrm{g}$ water and $0.4 \mathrm{mmol} / \mathrm{g}$ methanol molecules remaining after desorption at $373 \mathrm{~K}$. For water and methanol adsorption on $\mathrm{H}-[\mathrm{Al}] \mathrm{SBA}-15$, therefore, $\mathrm{SiOH}$ groups, which are weakly influenced by distantly incorporated framework aluminum species, are suggested to act as adsorption sites. Thus, the surface properties of micro- and mesoporous materials can be tuned in favour of one of the two adsorbates, water or methanol, over the other at elevated temperatures.

Acknowledgements The authors thank Marvin Stoll, Dorothea Häussermann, and Heike Fingerle (all University of Stuttgart) for nitrogen adsorption studies and ICP-OES measurements. Funded by the Deutsche Forschungsgemeinschaft (DFG, German Research Foundation) - Project ID 358283783 - SFB 1333.

Funding Open Access funding enabled and organized by Projekt DEAL.

Open Access This article is licensed under a Creative Commons Attribution 4.0 International License, which permits use, sharing, adaptation, distribution and reproduction in any medium or format, as long as you give appropriate credit to the original author(s) and the source, provide a link to the Creative Commons licence, and indicate if changes were made. The images or other third party material in this article are included in the article's Creative Commons licence, unless indicated otherwise in a credit line to the material. If material is not included in the article's Creative Commons licence and your intended use is not permitted by statutory regulation or exceeds the permitted use, you will need to obtain permission directly from the copyright holder. To view a copy of this licence, visit http://creativecommons.org/licenses/by/4.0/.

\section{References}

Anderson, M.W., Klinowski, J., Barrie, P.J.: Proton magic-angle-spinning NMR studies of the adsorption of alcohols on molecular sieve catalysts. J. Phys. Chem. 95(1), 235-239 (1991). https://doi. org/10.1021/j100154a046

Baerlocher, Ch., McCusker, L.B.: Database of zeolite structures. https ://www.izastructure.org/databases/. Accessed 6 Apr 2020

Batamack, P., Doremieux-Morin, C., Fraissard, J., Freude, D.: Broadline and high-resolution NMR studies concerning the hydroxonium ion in HZSM-5 zeolites. J. Phys. Chem. 95(9), 3790-3796 (1991). https://doi.org/10.1021/j100162a064

Caro, J., Noack, M.: Zeolite membranes-recent developments and progress. Microporous Mesoporous Mater. 115(3), 215-233 (2008). https://doi.org/10.1016/j.micromeso.2008.03.008

Dyballa, M., Becker, P., Trefz, D., Klemm, E., Fischer, A., Jakob, H., Hunger, M.: Parameters influencing the selectivity to propene in the MTO conversion on 10-ring zeolites: directly synthesized zeolites ZSM-5, ZSM-11, and ZSM-22. Appl. Catal. A 510, 233-243 (2016). https://doi.org/10.1016/j.apcata.2015.11.017

Dyballa, M., Obenaus, U., Blum, M., Dai, W.: Alkali metal ion exchanged ZSM-5 catalysts: on acidity and methanol-to-olefin performance. Catal. Sci. Technol. 8(17), 4440-4449 (2018a). https ://doi.org/10.1039/c8cy01032c

Dyballa, M., Pappas, D.K., Borfecchia, E., Beato, P., Olsbye, U., Lillerud, K.P., Arstad, B., Svelle, S.: Tuning the material and catalytic properties of SUZ-4 zeolites for the conversion of methanol or methane. Microporous Mesoporous Mater. 265, 112-122 (2018b). https://doi.org/10.1016/j.micromeso.2018.02.004

Dyballa, M., Pappas, D.K., Kvande, K., Borfecchia, E., Arstad, B., Beato, P., Olsbye, U., Svelle, S.: On how copper mordenite properties govern the framework stability and activity in the methaneto-methanol conversion. ACS Catal. 9(1), 365-375 (2019a). https ://doi.org/10.1021/acscatal.8b04437

Dyballa, M., Thorshaug, K., Pappas, D.K., Borfecchia, E., Kvande, K., Bordiga, S., Berlier, G., Lazzarini, A., Olsbye, U., Beato, P., Svelle, S., Arstad, B.: Zeolite surface methoxy groups as key 
intermediates in the stepwise conversion of methane to methanol. ChemCatChem 11(20), 5022-5026 (2019b). https://doi. org/10.1002/cctc. 201901315

Emsley, J.W., Feeney, J., Sutcliffe, L.H.: High Resolution nuclear magnetic resonance spectroscopy, vol. 1. Pergamon Press, Oxford (1965)

Engelhardt, G., Michel, D.: High-Resolution solid-state NMR of silicates and zeolites. Wiley, Hoboken (1987)

Flanigen, E.M., Bennett, J.M., Grose, R.W., Cohen, J.P., Patton, R.L., Kirchner, R.M., Smith, J.V.: Silicalite, a new hydrophobic crystalline silica molecular sieve. Nature 271(5645), 512-516 (1978). https://doi.org/10.1038/271512a0

Freude, D., Ernst, H., Wolf, I.: Solid-state nuclear magnetic resonance studies of acid sites in zeolites. Solid State Nucl. Magn. Reson. 3(5), 271-286 (1994). https://doi.org/10.1016/09262040(94)90003-5

Ghamami, M., Sand, L.B.: Synthesis and crystal growth of zeolite (NH4, TPA)-ZSM-5. Zeolites 3(2), 155-162 (1983). https://doi. org/10.1016/0144-2449(83)90205-1

Grünberg, B., Emmler, T., Gedat, E., Shenderovich, I., Findenegg, G.H., Limbach, H.-H., Buntkowsky, G.: hydrogen bonding of water confined in mesoporous silica MCM-41 and SBA- 15 studied by $1 \mathrm{H}$ solid-state NMR. Chemistry A 10(22), 5689-5696 (2004). https://doi.org/10.1002/chem.200400351

Haase, F., Sauer, J.: 1H NMR chemical shifts of ammonia, methanol, and water molecules interacting with broensted acid sites of zeolite catalysts: Ab-initio calculations. J. Phys. Chem. 98(12), 3083-3085 (1994). https://doi.org/10.1021/j100063a006

Haase, F., Sauer, J.: Interaction of methanol with Broensted acid sites of zeolite catalysts: an ab initio study. J. Am. Chem. Soc. 117(13), 3780-3789 (1995). https://doi.org/10.1021/ja00118a01 4

Harris, R.K., Mann, B.E.: NMR and the periodic table. Academic Press, Cambridge (1978)

Huang, J., van Vegten, N., Jiang, Y., Hunger, M., Baiker, A.: Increasing the Brønsted acidity of flame-derived silica/alumina up to zeolitic strength. Angew. Chem. Int. Ed. 49(42), 7776-7781 (2010). https ://doi.org/10.1002/anie.201003391

Hunger, M., Freude, D., Pfeifer, H.: Magic-angle spinning nuclear magnetic resonance studies of water molecules adsorbed on Brønstedand Lewis-acid sites in zeolites and amorphous silica-aluminas. J. Chem. Soc., Faraday Trans. 87(4), 657-662 (1991). https://doi. org/10.1039/FT9918700657

Hunger, M., Engelhardt, G., Weitkamp, J.: Cation migration in zeolite lanay investigated by multi-nuclear solid-state NMR. In: Weitkamp, J., Karge, H.G., Pfeifer, H., Hölderich, W. (eds.) Studies in surface science and catalysis, vol. 84, pp. 725-732. Elsevier, Amsterdam (1994)

Hunger, B., Heuchel, M., Matysik, S., Beck, K., Einicke, W.D.: Adsorption of water on ZSM-5 zeolites. Thermochim. Acta 269-270, 599-611 (1995a). https://doi.org/10.1016/0040-6031(95)02541-3

Hunger, M., Horvath, T., Engelhardt, G., Karge, H.G.: Multi-nuclear NMR study of the interaction of SiOHAl groups with cationic and neutral guest-molecules in dehydrated zeolites Y and ZSM-5. In: Beyer, H.K., Karge, H.G., Kiricsi, I., Nagy, J.B. (eds.) Studies in surface science and catalysis, vol. 94, pp. 756-763. Elsevier, Amsterdam (1995b)

Hunger, M., Horvath, T.: Multi-nuclear solid-state NMR study of the local structure of SiOHAl groups and their interaction with probemolecules in dehydrated faujasite, mordenite and zeolite ZSM-5. Ber Bunsen Phys Chem 99(11), 1316-1320 (1995). https://doi. org/10.1002/bbpc. 199500077

Hunger, M.: Multinuclear solid-state NMR studies of acidic and nonacidic hydroxyl protons in zeolites. Solid State Nucl. Magn. Reson. 6, 1-29 (1996)
Hunger, M., Horvath, T.: Adsorption of methanol on Brønsted acid sites in zeolite H-ZSM-5 investigated by multinuclear solid-state NMR spectroscopy. J. Am. Chem. Soc. 118(49), 12302-12308 (1996). https://doi.org/10.1021/ja962425k

Hunger, M., Ernst, S., Steuernagel, S., Weitkamp, J.: High-field 1H MAS NMR investigations of acidic and non-acidic hydroxyl groups in zeolites H-Beta, H-ZSM-5, H-ZSM-58 and H-MCM22. Microporous Mater. 6(5), 349-353 (1996). https://doi. org/10.1016/0927-6513(96)00043-0

Hunger, M.: Brønsted acid sites in zeolites characteriyed by multinuclear solid-state NMR spectroscopy. Catal. Rev.-Sci. Eng. 39(4), 345-393 (1997)

Hunger, B., Matysik, S., Heuchel, M., Einicke, W.-D.: Adsorption of methanol on ZSM-5 Zeolites. Langmuir 13(23), 6249-6254 (1997a). https://doi.org/10.1021/la970615i

Hunger, M., Sarv, P., Samoson, A.: Two-dimensional triple-quantum 23Na MAS NMR spectroscopy of sodium cations in dehydrated zeolites. Solid State Nucl. Magn. Reson. 9(2), 115-120 (1997b). https://doi.org/10.1016/S0926-2040(97)00051-9

Hunger, M., Schenk, U., Breuninger, M., Gläser, R., Weitkamp, J.: Characterization of the acid sites in MCM-41-type materials by spectroscopic and catalytic techniques. Microporous Mesoporous Mater. 27(2), 261-271 (1999). https://doi.org/10.1016/S1387 $-1811(98) 00260-1$

Jiang, Y., Huang, J., Dai, W., Hunger, M.: Solid-state nuclear magnetic resonance investigations of the nature, property, and activity of acid sites on solid catalysts. Solid State Nucl Magn Reson 39(34), 116-141 (2011). https://doi.org/10.1016/j.ssnmr.2011.03.007

Kalantzopoulos, G.N., Lundvall, F., Checchia, S., Lind, A., Wragg, D.S., Fjellvåg, H., Arstad, B.: In situ flow MAS NMR spectroscopy and synchrotron PDF analyses of the local response of the Brønsted acidic site in SAPO-34 during hydration at elevated temperatures. ChemPhysChem 19(4), 519-528 (2018). https:// doi.org/10.1002/cphc. 201700973

Kalantzopoulos, G.N., Lundvall, F., Thorshaug, K., Lind, A., Vajeeston, P., Dovgaliuk, I., Arstad, B., Wragg, D.S., Fjellvåg, H.: Factors Determining microporous material stability in water: the curious case of SAPO-37. Chem. Mater. 32(4), 1495-1505 (2020). https://doi.org/10.1021/acs.chemmater.9b04510

Kasai, P.H., Jones, P.M.: MAS-NMR spectroscopic study of water in zeolites. J. Mol. Catal. 27(1), 81-93 (1984). https://doi. org/10.1016/0304-5102(84)85072-5

Kim, H., Cho, H.J., Narayanan, S., Yang, S., Furukawa, H., Schiffres, S., Li, X., Zhang, Y.-B., Jiang, J., Yaghi, O.M., Wang, E.N.: Characterization of adsorption enthalpy of novel water-stable zeolites and metal-organic frameworks. Sci. Rep. 6(1), 19097 (2016). https ://doi.org/10.1038/srep19097

Lang, S., Benz, M., Obenaus, U., Himmelmann, R., Scheibe, M., Klemm, E., Weitkamp, J., Hunger, M.: Mechanisms of the $\mathrm{AlCl}_{3}$ modification of siliceous microporous and mesoporous catalysts investigated by multi-nuclear solid-state NMR. Top. Catal. 60(19), 1537-1553 (2017). https://doi.org/10.1007/s11244-017-0837-6

Lee, C.C., Gorte, R.J., Farneth, W.E.: Calorimetric study of alcohol and nitrile adsorption complexes in H-ZSM-5. J. Phys. Chem. B 101(19), 3811-3817 (1997). https://doi.org/10.1021/jp970711s

Luan, Z., Hartmann, M., Zhao, D., Zhou, W., Kevan, L.: Alumination and ion exchange of mesoporous SBA-15 molecular sieves. Chem. Mater. 11(6), 1621-1627 (1999). https://doi.org/10.1021/ $\mathrm{cm} 9900756$

Meynen, V., Cool, P., Vansant, E.F.: Verified syntheses of mesoporous materials. Microporous Mesoporous Mater. 125(3), 170-223 (2009). https://doi.org/10.1016/j.micromeso.2009.03.046

Olsbye, U., Svelle, S., Bjorgen, M., Beato, P., Janssens, T.V., Joensen, F., Bordiga, S., Lillerud, K.P.: Conversion of methanol to hydrocarbons: how zeolite cavity and pore size controls product 
selectivity. Angew. Chem. Int. Ed. Engl. 51(24), 5810-5831 (2012). https://doi.org/10.1002/anie.201103657

Pappas, D.K., Borfecchia, E., Dyballa, M., Pankin, I.A., Lomachenko, K.A., Martini, A., Signorile, M., Teketel, S., Arstad, B., Berlier, G., Lamberti, C., Bordiga, S., Olsbye, U., Lillerud, K.P., Svelle, S., Beato, P.: Methane to methanol: structure-activity relationships for Cu-CHA. J. Am. Chem. Soc. 139(42), 14961-14975 (2017). https://doi.org/10.1021/jacs.7b06472

Pope, C.G.: Adsorption of methanol and related molecules on zeolite H-ZSM-5 and silicalite. J. Chem. Soc., Faraday Trans. 89(7), 1139-1141 (1993). https://doi.org/10.1039/FT9938901139

Prodinger, S., Derewinski, M.A., Vjunov, A., Burton, S.D., Arslan, I., Lercher, J.A.: Improving stability of zeolites in aqueous phase via selective removal of structural defects. J. Am. Chem. Soc. 138(13), 4408-4415 (2016). https://doi.org/10.1021/jacs.5b12785

Ratcliffe, C.I., Ripmeester, J.A., Tse, J.S.: NMR chemical shifts of dilute $1 \mathrm{H}$ in inorganic solids. Chem. Phys. Lett. 120(4), 427-432 (1985). https://doi.org/10.1016/0009-2614(85)85634-7

Ravi, M., Ranocchiari, M., van Bokhoven, J.A.: The direct catalytic oxidation of methane to methanol-a critical assessment. Angew. Chem. Int. Ed. 56(52), 16464-16483 (2017). https://doi. org/10.1002/anie.201702550

Salehirad, F., Anderson, M.W.: Solid-state NMR studies of adsorption complexes and surface methoxy groups on methanol-sorbed microporous materials. J. Catal. 177(2), 189-207 (1998). https:// doi.org/10.1006/jcat.1998.2096

Sauer, J.: Nature and properties of acidic sites in zeolites revealed by quantum chemical ab initio calculations. In: Fejes, P., Kalló, D. (eds.) Processdings of the international symposion on zeolite catalysis: Siófok (Hungary), vol. 31, pp. 19-24. Szeged, ACTA Physica et Chemica Szegediensis (1985)

Schmeling, T., Strey, K.: Equilibrium Vapor pressure measurements for the $\mathrm{n}$-alcohols in the temperature range from $-30{ }^{\circ} \mathrm{C}$ to +30 ${ }^{\circ}$ C. Ber. Bunsen. Phys. Chem. 87(10), 871-874 (1983). https:// doi.org/10.1002/bbpc.19830871008

Talha, Z., Bachir, C., Ziri, S., Bellahouel, S., Bengueddach, A., Villièras, F., Pelletier, M., Weidler, P.G., Hamacha, R.: Al-rich ordered mesoporous silica SBA-15 materials: synthesis, surface characterization and acid properties. Catal. Lett. 147(8), 21162126 (2017). https://doi.org/10.1007/s10562-017-2103-8

Thamm, H.: Calorimetric study on the state of C1-C4 alcohols sorbed on silicalite. J. Chem. Soc., Faraday Trans. 85(1), 1-9 (1989). https://doi.org/10.1039/F19898500001

Tian, P., Wei, Y., Ye, M., Liu, Z.: Methanol to olefins (MTO): from fundamentals to commercialization. ACS Catal. 5(3), 1922-1938 (2015). https://doi.org/10.1021/acscatal.5b00007
Wang, M., Jaegers, N.R., Lee, M.-S., Wan, C., Hu, J.Z., Shi, H., Mei, D., Burton, S.D., Camaioni, D.M., Gutiérrez, O.Y., Glezakou, V.-A., Rousseau, R., Wang, Y., Lercher, J.A.: Genesis and stability of hydronium ions in zeolite channels. J. Am. Chem. Soc. 141(8), 3444-3455 (2019). https://doi.org/10.1021/jacs.8b07969

Wang, Z., Jiang, Y., Rachwalik, R., Liu, Z., Shi, J., Hunger, M., Huang, J.: One-step room-temperature synthesis of [Al]MCM-41 materials for the catalytic conversion of phenylglyoxal to ethylmandelate. ChemCatChem 5(12), 3889-3896 (2013a). https://doi. org/10.1002/cctc. 201300375

Wang, Z., Pokhrel, S., Chen, M., Hunger, M., Mädler, L., Huang, J.: Palladium-doped silica-alumina catalysts obtained from doubleflame FSP for chemoselective hydrogenation of the model aromatic ketone acetophenone. J. Catal. 302, 10-19 (2013b). https:// doi.org/10.1016/j.jcat.2013.02.017

Wang, Z., Jiang, Y., Hunger, M., Baiker, A., Huang, J.: Catalytic performance of Brønsted and lewis acid sites in phenylglyoxal conversion on flame-derived silica-zirconia. ChemCatChem 6(10), 2970-2975 (2014). https://doi.org/10.1002/cctc.201402397

Wang, Z., Kim, K.-D., Zhou, C., Chen, M., Maeda, N., Liu, Z., Shi, J., Baiker, A., Hunger, M., Huang, J.: Influence of support acidity on the performance of size-confined Pt nanoparticles in the chemoselective hydrogenation of acetophenone. Catal. Sci. Technol. 5(5), 2788-2797 (2015). https://doi.org/10.1039/C5CY00214A

Wang, Z., Jiang, Y., Stampfl, C., Baiker, A., Hunger, M., Huang, J.: NMR spectroscopic characterization of flame-made amorphous silica-alumina for cyclohexanol and glyceraldehyde conversion. ChemCatChem 12(1), 287-293 (2020). https://doi.org/10.1002/ cctc. 201901728

Xu, M., Wang, W., Seiler, M., Buchholz, A., Hunger, M.: Improved Brønsted acidity of mesoporous [Al]MCM-41 material treated with ammonium fluoride. J. Phys. Chem. B 106(12), 3202-3208 (2002). https://doi.org/10.1021/jp014222a

Zhang, K., Lively, R.P., Noel, J.D., Dose, M.E., McCool, B.A., Chance, R.R., Koros, W.J.: Adsorption of water and ethanol in MFItype zeolites. Langmuir 28(23), 8664-8673 (2012). https://doi. org/10.1021/la301122h

Publisher's Note Springer Nature remains neutral with regard to jurisdictional claims in published maps and institutional affiliations.

\section{Affiliations}

\section{Zheng $\mathrm{Li}^{1} \cdot$ Carolin Rieg ${ }^{1} \cdot$ Ann-Katrin Beurer ${ }^{1} \cdot$ Michael Benz $^{1} \cdot$ Johannes Bender ${ }^{2} \cdot$ Christof Schneck $^{3} \cdot$ Yvonne Traa $^{1}$. Michael Dyballa ${ }^{1} \mathbb{D} \cdot$ Michael Hunger $^{1}$}

1 Institute of Chemical Technology, University of Stuttgart, Pfaffenwaldring 55, 70569 Stuttgart, Germany

2 Institute of Chemical Process Engineering, University of Stuttgart, Böblinger Str. 78, 70199 Stuttgart, Germany
3 Institute of Inorganic Chemistry, University of Stuttgart, Pfaffenwaldring 55, 70569, Stuttgart, Germany 